\title{
Posturas formativas frente a la disciplina gastronómica en el contexto iberoamericano y colombiano: Retos y posibilidades
}

\section{Training views for gastronomic discipline in the Ibero-American and colombian context: Challenges and possibilities}

\author{
María Mercedes Gómez Correa \\ Magíster en Historia y Cultura de la Alimentación \\ Universidad Católica Luis Amigó \\ Medellín, Colombia \\ Correo electrónico: maria.gomezco@amigo.edu.co
}

Recibido 12 de agosto de 2016; aprobado 30 de septiembre de 2016

\section{Cómo citar este artículo:}

Gómez, M.M. (2017). Posturas formativas frente a la disciplina gastronómica en el contexto iberoamericano y colombiano: Retos y posibilidades. Espiral, Revista de Docencia e Investigación, 7(1), 27 - 60.

\section{Resumen}

Objetivo. Este artículo de revisión bibliográfica se propone hacer un estado del arte sobre las relaciones que se han establecido entre la reflexión pedagógica y los programas de formación gastronómica en Colombia, a través de una revisión concienzuda, sistemática y crítica de la producción documental iberoamericana publicada sobre este tema.

Metodología. Se realiza una evaluación y selección de las fuentes consultadas en su contenido y estructura metodológica para establecer una postura formativa frente al carácter profesional reciente de algunos programas gastronómicos. La gastronomía en el contexto colombiano ha sido concebida desde la perspectiva formativa, específicamente como una capacitación para el trabajo de carácter técnico y tecnológico.

Resultados. Actualmente algunos programas de gastronomía han adquirido la condición de profesional, lo que plantea una nueva postura frente a esta disciplina que conlleva una complementariedad de contenidos y métodos, se requiere una delimitación conceptual, metodológica y de contenidos clara, entre las técnicas, las tecnologías y las carreras profesionales en gastronomía vs culinaria, es necesario desarrollar una reflexión pedagógica de la enseñanza de la gastronomía en Colombia que considere temáticas de investigación y estructure un discurso en torno al método, en un contexto interdisciplinar, flexible y contextualizado en el mundo actual.
Palabras clave: Disciplina gastronómica/culinaria, gastronomía profesional, formación gastronómica, reflexión pedagógica/formativa.

\section{Abstract}

Objective. and aim. The purpose of this bibliographic review article is to make a state of the art about the relations that have been established between the pedagogical reflection and the programs of gastronomic formation in Colombia, through a conscientious, systematic and critical revision of the Ibero-American documentary production published about this.

Methodology. An evaluation and selection of the sources consulted in its content and methodological structure is carried out to establish a formative position against the recent professional character of some gastronomic programs. Gastronomy in the Colombian context has been conceived from the formative perspective specifically as a training for technical and technological work.

Results. Nowadays, some gastronomy programs have gained a professional status, which poses a new attitude towards this discipline that leads to a complementarity of content and method. A clear concept, methodological and content boundary between techniques, technologies and professional careers in gastronomy vs culinary are required. It is necessary to develop a pedagogical reflection of the teaching of gastronomy 
in Colombia that considers research topics and builds a discourse around the discipline, in an interdisciplinary, flexible and contextualized context in the current world.

Keywords: Gastronomic / culinary discipline, professional gastronomy, gastronomic training, pedagogic / formative reflection.

\section{Introducción}

“Estudiar gastronomía no es como lo pintan" (2014), titula el artículo del periódico El Tiempo que evidencia el estado actual de la gastronomía y la formación gastronómica en Colombia. Aclara el diario que, aunque existe un boom mediático en torno a los cocineros y hay más interés por parte de la población en formarse en la disciplina gastronómica o la culinaria, hay un desconocimiento general frente a lo que conlleva una disciplina de este tipo. Primero que todo, está la poca claridad entre gastronomía y culinaria (Ayora, 2014, p. 60), segundo, está la legitimación de la gastronomía únicamente desde la culinaria, lo que reduce las posibilidades de desempeño en la disciplina gastronómica, tercero, también existe la tendencia en quienes estudian gastronomía profesional de creer que en cuanto terminen la carrera, van a ocupar cargos de mando y también a utilizar la disciplina como escampadero, pensando que solo implica cocinar y que por ende es fácil.

A todos estos retos se suma la carencia de discursos formativos en torno a la disciplina gastronómica que aboguen por su dignificación (Mejía, Mejia, \& Bravo, 2014), de modo que adquiera el estatus de conocimiento científico del que gozan otras tantas disciplinas, sin embargo, y aprovechando el boom actual de la gastronomía, este estado del arte propone rastrear en la web toda aquella documentación iberoamericana y colombiana del 2000 en adelante, que haga referencia a posturas frente a la formación en gastronomía, sea implícita o explícitamente y que den cuenta de experiencias formativas para la misma. Para este rastreo se plantearon categorías que surgieron de la documentación, con el fin de abstraer y clasificar la información para el corpus de este artículo.

El primer apartado "Aclaraciones previas sobre los conceptos de disciplina gastronómica y artes culinarias" responde a la evidencia que dejan los análisis documentales frente a la concepción malinterpretada de gastronomía vs arte. El segundo apartado es un rastreo histórico de la formación en gastronomía que permite contextualizar y conceptualizar la problematización formativa de la disciplina gastronómica en Colombia. El tercer apartado expone algunas de las posturas intelectuales y analíticas que se han hecho en el marco de la gastronomía, la culinaria y los alimentos en torno a la formación en Iberoamérica, y el cuarto apartado analiza el contexto colombiano frente a la reflexión formativa en gastronomía, para así postular un debate sobre los retos, necesidades y estrategias en la construcción de un discurso que entable un diálogo entre la gastronomía y la pedagogía.

Este estudio plantea un punto de partida en la construcción de un discurso formativo que aborde la praxis pedagógica en gastronomía, no como una disciplina propia del afán del mundo actual, sino como una disciplina que sea capaz de pensarse a sí misma y en sí misma, y que además articule sus contenidos a otros saberes.

\section{Desarrollo}

\section{Aclaraciones previas sobre los conceptos de disciplina gastronómica y artes culinarias}

La gastronomía es definida como una disciplina que estudia la relación del hombre y la cultura, tomando como eje la alimentación, esta definición alude al hecho de que el saber gastronómico está implicado e implícito con muchas otras ciencias y saberes. Ya lo expresaba Brillat-Savarín desde 1825, con su obra póstuma, Fisiología del gusto: 
Entiéndase por gastronomía el conocimiento razonado de cuanto al hombre se refiere en todo lo que respecta a la alimentación. Tiene por objeto velar por la conservación del hombre empleando los mejores alimentos. Esto lo consigue dirigiendo con principios fijos a los que buscan, suministran o preparan cosas capaces de convertirse en alimentos. La gastronomía está en relación con las materias siguientes:

Con la historia natural, por la clasificación que practica de las substancias alimenticias. Con la física, por el examen de sus partes componentes y cualidades. Con la química, por los diversos análisis y descomposiciones que les hace experimentar. Con la cocina, por el arte de guisarlas y de hacerlas agradables al gusto. Con el comercio, porque se ocupa en buscar lo que consume al precio más barato posible y en expender con las mayores ventajas lo que presenta a la venta. Por último, con la economía política, por los recursos que presenta a fin de recaudar contribuciones y por las facilidades de cambios que entre las naciones establecen. La vida entera está gobernada por la gastronomía: pues el llanto del recién nacido llama al pecho que lo amamanta y el moribundo todavía recibe con cierto placer la pócima suprema que por desgracia ya no puede digerir. También se ocupa la gastronomía de todas las jerarquías sociales, porque si dirige los banquetes de soberanos reunidos, calcula así mismo el número de minutos necesarios a fin de que no hierva más que lo preciso un huevo convenientemente pasado por agua.

El objeto material de la gastronomía abraza todo cuanto es comible, su fin directo es la conservación del individuo y sus medios de ejecución están constituidos por la labranza que produce, el comercio que verifica transacciones, la industria que elabora productos y la experiencia que inventa cómo debe disponerse todo para su aplicación más ventajosa (2014, p. 51).

Sin embargo, el término gastronomía desde su concepción disciplinar, no deja de amalgamarse con el concepto de arte culinario, lo que ha dado lugar a una malinterpretación del perfil profesional del gastrónomo y del objeto de estudio de la gastronomía. Para hacer frente a una reflexión pedagógica en la enseñanza de la gastronomía, es necesario hacer la diferenciación entre lo que es la gastronomía como disciplina o saber y el arte culinario. "La gastronomía se refiere a la relación del hombre con su entorno, tomando como fundamento la alimentación" (Brillat-Savarin, 2014, p. 51), mientras que el arte culinario o la culinaria, es una forma de expresión artística, creativa, novedosa, recursiva e inventiva de preparar los alimentos, a propósito de esto, cabe aclarar que todo gastrónomo debe tener competencias para las artes culinarias, mientras que no todo cocinero es un gastrónomo profesional necesariamente.

Para construir una postura pedagógica y una aclaración frente a la enseñanza y profesionalización de la gastronomía en Colombia, es indispensable aclarar que, la disciplina gastronómica se enfoca en comprender el entorno alimentario humano (Unigarro, 2010, p. 15), lo que implica un cuerpo de conocimientos más amplio que el del arte culinario, podría afirmarse entonces que el arte culinario necesita de la disciplina gastronómica y de sus contenidos teóricos para poder consolidarse como otro campo o rama de conocimiento entre el saber gastronómico a partir de un enfoque artístico. La gastronomía en Colombia desde los inicios de su enseñanza ha sido denominada gastronomía profesional o gastronomía y cocina profesional, sin embargo, más que gastronomía lo que se ha impartido en Colombia desde los años 70, son técnicas, artes culinarias o culinaria.

\section{Antecedentes históricos de la formación y profesionalización de la gastronomía en Colombia}

Desde principios del siglo XX se hacen presente en Colombia, platos y chefs de origen francés en las mesas de las clases altas colombianas; cuestiones que permanecieron exclusivas y desconocidas para la gran mayoría de la población y evidenciándose como lo expresa María Fernanda Cristancho (2013), en los siguientes aspectos: 
La ausencia de escuelas de cocina que departieran la enseñanza de un saber culinario, un acotado número de restaurantes sofisticados, los pocos chefs y cocineros con formación profesional que estuvieran al mando de las cocinas de hoteles y restaurantes del país. Además de eso, quienes tenían proximidad y conocimiento de este tipo de cocina, eran las contadas damas de clase alta, que hacían uso cotidiano del saber para alimentar a sus familias (2013, p. 19).

Para referirse a la evolución de formación en alta cocina en Colombia, toman relevancia las tres últimas décadas, como un periodo dinámico y de transformación para el campo gastronómico y culinario. Es en estos años cuando acontecen hechos significativos que dan oportunidad a nuevas dinámicas culinarias.

Es importante recalcar el carácter de mestizaje alimentario que conllevan los hábitos alimentarios y las preparaciones culinarias colombianas, lo que lo convierte en un gran potencial de estudios alimentarios y gastronómicos, sin embargo, en cuanto a estructuración y consolidación de una enseñanza para y por la gastronomía, es recientemente que "Colombia empieza a insertarse en las lógicas gastronómicas mundiales" (Cristancho, 2013, p. 19).

Cabe destacar la labor del SENA como institución pionera de la formación culinaria y, por ende, de la formación de los primeros docentes en el área, lo que ha desembocado en nuevas dinámicas de capacitación para la disciplina gastronómica y su profesionalización. Actualmente existen aproximadamente 29 programas de gastronomía en Colombia, de los cuales, más o menos 6 son de carácter profesional.

Aunque posteriormente, otras escuelas también aportaron a la dinamización de la gastronomía colombiana, hay que admitir que el SENA fue la primera institución en dar una educación formal sobre culinaria, adoptando un esquema de cocina científica y estructurada.

Durante muchos años fuimos los únicos. Uno puede decir sin ningún temor que, en todos los restaurantes de calidad del país, en este momento, la mitad de la gente ha pasado por el SENA"; así lo asegura Fernando Argüello, coordinador de Formación Profesional del Centro Nacional de Hotelería, Turismo y Alimentos de la Regional Distrito Capital.

La primera escuela que empezó en formar gente en cocina fue el SENA y nosotros la hicimos basados en la formación en cocina y charcutería que nos dio la Escuela CERIA de Bélgica; el SENA contrató a los expertos que vinieron a Colombia a montar unos programas de cocina y se empezó a hacer la formación de cocineros. Antes de eso no había capacitación en el área y la gente contrataba a señoras que sabían cocinar y las ponían en los restaurantes. Estoy hablando más o menos del año 68 (SENA, 2014).

El SENA dio inicio a la formación de colombianos en áreas de cocina y afines a finales de la década de los sesenta en un sitio que se denominó Centro Nacional de Hotelería en Bogotá. Allí se dictaban talleres de cocina, servicio de habitación, recepción de huéspedes, atención en la barra de licores y de cómo poner la mesa para gusto de comensales e invitados, y aun hoy, continúa con su labor de formar colombianos en estas áreas.

Inicialmente, ser cocinero o estudiar cocina soportaba un desprestigio en Colombia, no obstante, a finales de los noventa, cuando ingresa a los hogares la televisión por suscripción, donde había posibilidad de ver programas de índole más variado en cuanto a temas alimentarios y culinaria, comienza un auge de interés gastronómico en Colombia, es interesante observar que en las propuestas televisivas de Argentina o Estados Unidos, había para la década de los noventa, canales dedicados exclusivamente a la gastronomía y la culinaria, en contraste con los canales colombianos, cuyos programas de cocina siempre hacían parte de un pequeño segmento de otro programa que generalmente se trasmitía en horas de la mañana y que pueden dar una idea del público al que iban dirigidos. 


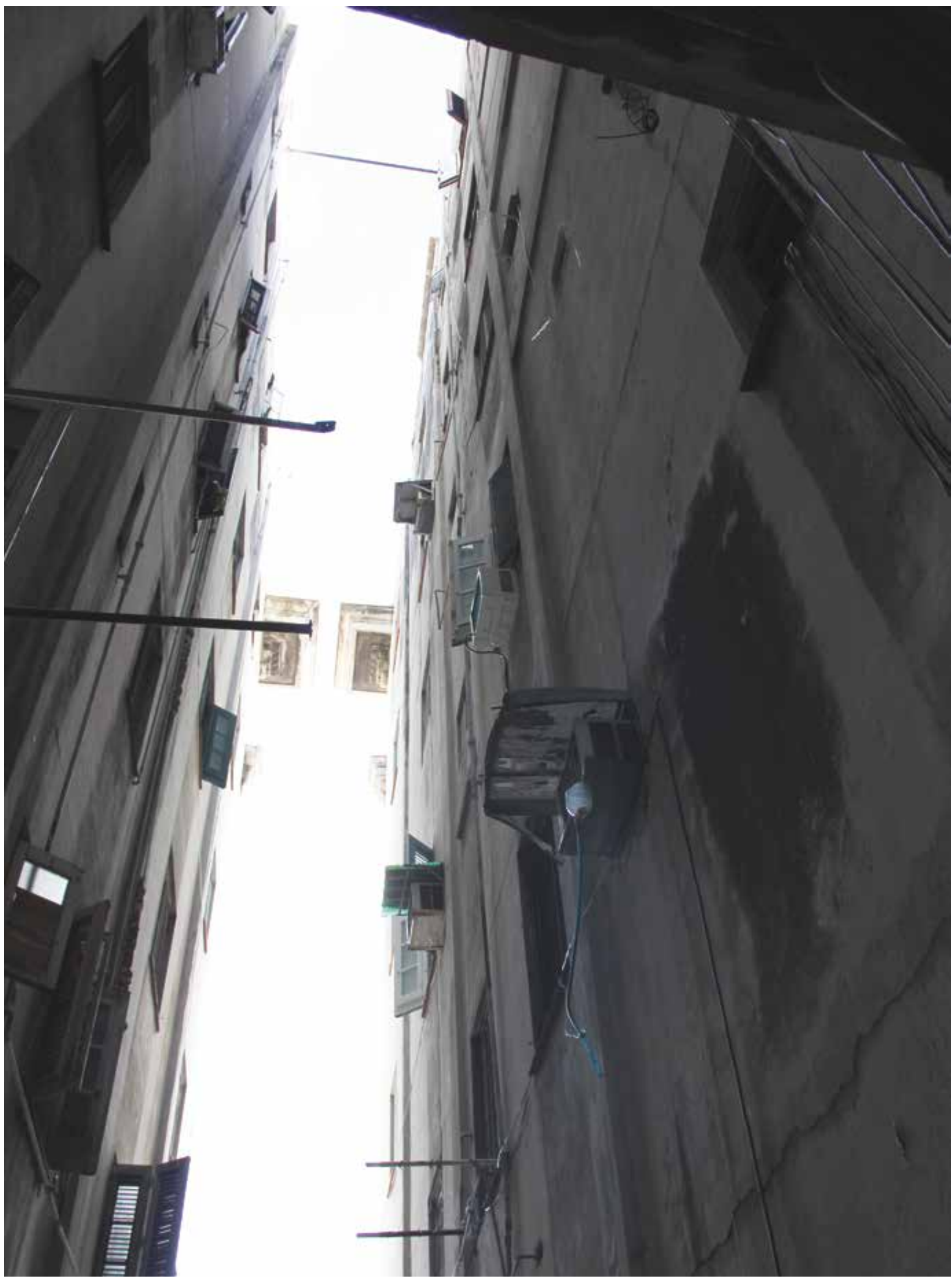


Con este boom noventero por la culinaria y la gastronomía, se dieron nuevas propuestas educativas desde el SENA, manteniendo su esencia, pero reforzando la posibilidad de una educación más incluyente con la población colombiana y capacitando a sus instructores en Europa y certificándolos como instructores internacionales y se podría decir hoy que la formación y talento de los egresados de los programas de formación en cocina del SENA hacen parte de los mejores restaurantes de Colombia y el mundo. También, cabe mencionar que los primeros aprendices del SENA fueron eventualmente los primeros docentes de cocina y, por ende, pioneros de nuevas propuestas de gastronomía y culinaria local.

Del 2000 para acá, se introdujeron en las principales ciudades nuevas propuestas y conceptos culinarios, no solo nacionales, sino internacionales, esto derivó en un comensal más erudito y exigente frente a la gastronomía y la culinaria. Este nuevo conocimiento de esquemas alimentarios distintos a los cotidianamente conocidos y el buen momento económico del país, hizo posible la inversión extranjera y propuestas más audaces e innovadoras gastronómicamente hablando.

También para la década del 2000 surgen en Colombia las carreras profesionales en gastronomía, normalmente en instituciones privadas, con un alto costo de matrícula y con una duración de 4 a 5 años, generalmente el enfoque que le dan a estas profesionalizaciones hacen referencia a la carga de contenidos investigativos en contraste con la carga investigativa que se pueda dar en una técnica o tecnología. Sin embargo, para dar cuenta de esta profesionalización se debe aclarar que, en las carreras técnicas se orientan y capacitan los estudiantes en el ámbito culinario, mientras que en las tecnologías "hay una finalidad de formar profesionales capaces de desempeñar ocupaciones que estén acordes con los avances tecnológicos, con énfasis en la práctica y la investigación" (Nullvalue, 1999) (UNESCO, 2000).
Frente a estos sistemas de aprendizaje, aún existe un desconocimiento general en Colombia, sobre todo, en el ámbito culinario y gastronómico; según la Ley 30 de diciembre 28 de 1992 se organiza el servicio público de la Educación Superior y se establecen las modalidades de profesionales universitarios y de carreras técnicas y tecnológicas; queda establecido entonces y en teoría, la diferencia entre carreras técnicas, tecnológicas y universitarias desde la duración del estudio y la fundamentación científica, humanística e investigativa de cada una. No obstante, entre esta delimitación los contenidos del arte culinario y la gastronomía se resienten, sobre todo cuando surge la propuesta de la profesionalización de la culinaria.

Para la profesionalización de las artes culinarias y la gastronomía ha evidenciado que, aunque existen escuelas formando "profesionales" en gastronomía y cocina desde hace más de una década, aun no es claro para el Estado, los bachilleres, los futuros profesionales y para las mismas instituciones académicas, lo que conlleva la profesionalización de la gastronomía, en contraste con países, como México, España y Francia que han consolidado de manera efectiva sus profesionalizaciones en culinaria, incluso llegando a crear especializaciones y posgrados referentes a temáticas gastronómicas. La Ley 30 es clara frente a la diferencia con la educación universitaria, y consigna que un profesional universitario estudia de cuatro a cinco años una carrera para aprender lo mismo que un técnico y un tecnólogo y, además, conoce el porqué de ese oficio, su importancia y aporte que brinda a la sociedad.

Se podría decir que en lo que concierne a la profesionalización gastronómica, todavía nos encontramos en una especie de edad media, casi ingresando a un renacimiento, no se podría de ninguna manera negar el aporte de las técnicas y las tecnologías de cocina en el ámbito educativo gastronómico, sin embargo, en ese afán de educar para el trabajo, el término gastronomía fue reducido meramente a culinaria 
y esto lo podemos rastrear en el marcado interés de las economías en vías de desarrollo, en el mundo en general, se prioriza en una educación tecnológica articulada al desarrollo de las naciones, sin embargo, en Colombia siempre han sido exaltadas las carreras universitarias sobre las técnicas y tecnologías, influenciado por el factor salario, es por esto que algunos académicos se han pronunciado al respecto:

Los académicos del país hacen un llamado para que este sistema de formación no se mire como una educación de segunda. Es más, con el fin de definir con más claridad su perfil y función social, varias entidades de educación técnica y tecnológica presentaron una propuesta al Gobierno Nacional. Esta propuesta pretende que las denominadas universidades sean solamente aquellas instituciones que se dediquen a la investigación, mientras que se podrían llamar Escuelas Profesionales, a las instituciones y politécnicos de educación técnica y tecnológica que forman a profesionales en áreas de la ingeniería, afirmó Francisco Núñez, rector del Instituto Tecnológico Inespro (Nullvalue, 1999).

Según la definición general, los profesionales técnicos o tecnólogos estarían formados en la ingeniería y las ciencias exactas, incluso esto se puede rastrear desde el origen del SENA que dio prioridad de formación, en las áreas industrial, electrónica, agropecuaria, metalmecánica y. donde hay posibilidad de complementar estudios en politécnicos especializados en carreras cortas y largas. No obstante, en contraposición a la definición más exacta de lo que supone una técnica y una tecnología, en Colombia se hace una malinterpretación de la definición, ya que lo que están formando son "profesionales intermedios en áreas muy específicas, ya sea de carácter administrativo, social u operativo. Las carreras técnicas profesionales se caracterizan por integrar conocimientos científicos, tecnológicos, empresariales y comunitarios" (Nullvalue, 1999). Ahora bien, frente a esta confusa interpretación de los conceptos de técnicas y tecnologías, es imprescindible ubicarse en el contexto colombiano, cuyo entorno ha favorecido la educación en conocimientos propiamente prácticos que han permitido incorporar al mercado laboral de manera rápida, estudiantes con competencias para ejercer trabajos puntuales y prácticos. De hecho, en Colombia se favorece a los técnicos o tecnólogos (profesionales intermedios) desde los perfiles profesionales creados por las empresas, incluso tienen la posibilidad de profesionalizarse con semestres complementarios y de validar parte de su carrera profesional con las carreras intermedias. Se podría afirmar que el pensum de las carreras intermedias es similar al de las universitarias con la diferenciación del énfasis en la práctica que predomina en las técnicas y tecnologías.

Con respecto a las carreras profesionales en gastronomía y culinaria, y en algunas entrevistas realizadas al gremio, da la sensación de que son concebidas como técnicas o tecnologías alargadas, que no aportan un nuevo conocimiento a nivel profesional más allá de las carreras intermedias, porque se cree que indiscriminadamente del tiempo que se estudie culinaria o gastronomía, se puede llegar a ser un profesional. No se ha hecho una delimitación clara frente a lo que conlleva tener un rol de técnico, tecnólogo o profesional en el ámbito culinario y gastronómico nacional, con esto no se pretende desacreditar el valor del gastrónomo o cocinero empírico, técnico o tecnólogo que se ha preocupado por su aprendizaje autónomo y que merece, por su entrega y esfuerzo laboral al campo, denominarse un profesional, porque a modo personal, ser profesional, más allá de los estudios, implica un amor, una entrega, un perfeccionamiento y una relación estable con un saber hacer específico. Incluso cabe resaltar que han sido las escuelas técnicas y tecnológicas quienes más posibilidades han brindado a la gente, para formarse en ámbitos culinarios, dado su bajo coste, ya que generalmente están financiadas por el Estado, a excepción de algunas privadas que cobran un poco más por matrícula. También han sido las escuelas de profesionalización intermedia pioneras en la flexibili- 
zación de sus currículos y horarios, fomentando así el acceso de todos los colombianos a la educación intermedia y superior.

Ante todo, ha habido un perfeccionamiento de estas técnicas y tecnologías que, al estar adscritas al Estado, están mejor informadas sobre las exigentes dinámicas laborales que implica el contexto global. En Colombia se hacen esfuerzos, desde estas carreras intermedias, para formar líderes del siglo XXI, con altos niveles de adaptabilidad, flexibilización, creatividad, innovación, emprendimiento, trabajo cooperativo y con conocimientos globales, que en síntesis sería lo que perseguiría la profesionalización en gastronomía desde ámbitos investigativos, teóricos y prácticos.

En Colombia el perfil profesional del técnico y el tecnólogo se encuentra sujeto a las demandas laborales ejercidas por los empresarios y es entendible en este país, dada las condiciones socioeconómicas. La gran mayoría de la gente debe formarse en algo rápidamente para poder ingresar al mercado laboral o montar empresa y así poder subsistir. Mucha gente lo logra, incluso sin tener algún estudio previo, sin embargo, en estas dinámicas históricas y conceptuales y en la priorización de los perfiles profesionales diseñados por las empresas, se ha perdido el valor innovador, creativo e investigativo de la gastronomía, y por ende en la consolidación del carácter profesional de la gastronomía.

Aun cuando ya existen programas profesionales en gastronomía y cocina, con una duración de cuatro o cinco años, y con énfasis muy marcados en artes, administración o química, no se evidencia aun un quiebre de la gastronomía con las artes culinarias, ni una reflexión en torno a lo que conllevaría la profesionalización en gastronomía, en cuanto a fundamentos ontológicos, epistemológicos y de metodología, mucho menos se evidencia una reflexión pedagógica o postura en torno a la enseñanza de la gastronomía. Cuando se observan los pensum de los distintos programas de gastronomía pro- fesional a nivel nacional, se evidencia que, en comparación con los programas técnicos y tecnológicos hay más contenidos de índole investigativo en la profesionalización, sin embargo, en la búsqueda de productos de investigación gastronómica, es poco lo que arrojan las bases de datos, se puede afirmar que, si hay investigación, pero es poca y casi siempre enfocada a la cocina nacional, que aunque importante, no es la única posibilidad de investigación que ofrece la disciplina gastronómica, incluso estas investigaciones carecen de rigurosidad, por ser simplemente descripciones de platos descontextualizados y desarraigados culturalmente. En lo concerniente al periodismo o producción de revistas gastronómicas, desde el XIX, la prensa ha abierto pequeños espacios en sus columnas para expresiones gastronómicas, sin embargo, no fue hasta hace 8 años que surgen revistas con el propósito de reafirmar la gastronomía y las artes culinarias, ya no solo como un saber hacer del cotidiano, si no como una cuestión de carácter disciplinar y profesional.

Es evidente que el tema culinario y gastronómico se encuentra popularizado actualmente en el ámbito colombiano, incluso gracias a esto, se han visto esfuerzos entre los cocineros por resaltar la gastronomía colombiana e incluso igualarla a los esquemas internacionales, rescatando productos desacreditados y reconociendo en Colombia una despensa biológica natural, llena de matices indígenas, españoles, negros y árabes, de los cuales innovar. El interés gastronómico ha permeado en los grupos sociales, específicamente en la clase media y alta, creando una nueva demanda por productos y servicios de este tipo.

Aunque rudimentaria la investigación gastronómica, desde la antropología social (ciencias sociales) y el periodismo gastronómico ya hay muy buenos productos de investigación referente a tradiciones alimentarias de cada región, que resaltan el mosaico cultural que es Colombia y contextualizan las distintas preparaciones de cada región; un muy buen registro 
de esto es la Biblioteca básica de cocinas tradicionales de Colombia, lanzadas por el Ministerio de Educación entre el 2012 y 2013, y que da cuenta no solo de los recetarios típicos de la regiones sino también del contexto cultural donde se desarrollan dichas preparaciones, así como todo un rastreo histórico de las culturas que permearon el universo alimentario local y que dieron lugar al mestizaje alimentario. Porque en Colombia no se puede hablar de gastronomía, sino de gastronomías

Aun cuando hoy, ya hay un buen registro de las gastronomías colombianas y los colombianos están aceptando de mejor gana, propuestas alimentarias novedosas e incluso considerando estudiar gastronomía, se percibe una carencia en cuanto a la concepción del saber disciplinar gastronómico, lo que ha reducido las posibilidades de indagación e innovación de la gastronomía en el ámbito colombiano. Primero que todo, hay que considerar que "la institucionalización del saber culinario, pese a ser incipiente y estar en exploración, pronostica un cambio paulatino del pensamiento de creación de comida y cocinas del país" (Cristancho, 2013, p. 21). También se debe considerar que, aunque ya existen programas profesionales en gastronomía, daría la impresión cuando se recurre a sus currículos que faltó rigurosidad en cuanto la conformación de dichas profesionalizaciones, se siguió dando relevancia a la práctica sobre le teoría y las investigaciones se limitaron simplemente al rescate patrimonial de las cocinas colombianas y a la cocina de autor sin fundamento o conceptualización, cocinar por cocinar. A esto se suma que una carrera es mucho más llamativa en Colombia, que una técnica o una tecnología y aunque desafortunadamente las carreras profesionales en cocina son costosas, no ha impedido que algunos estudiantes la consideren una disciplina fácil y de poca potencia teórica, creyendo erróneamente que por ser de carácter profesional van a tener un mejor sueldo en cuanto se gradúen en comparación con los estudiantes de carreras inter- medias. Sin embargo, en la gastronomía es bien conocido que el sueldo depende de quien pueda ofrecer un valor agregado como gastrónomo y también de la trayectoria. El panorama actual es que hay demasiados cocineros sin nada nuevo que ofrecer, sujetos a las empresas que piden cocineros que sean capaces de cumplir funciones mecánicas y puntuales, en jornadas extenuantes y con sueldos cuestionables. Aun así, no hay quien detenga la horda de futuros cocineros o gastrónomos que cada día llenan las aulas-cocinas de los programas de gastronomía profesional, sin entender realmente de qué se trata la disciplina desde el ámbito de formación profesional.

Es por esto que este artículo se propone una reflexión desde la formación profesional en gastronomía, y aunque no hay evidencia documental colombiana sobre lo que dice la pedagogía en torno a la formación en la disciplina gastronómica, es claro que, la profesionalización en la disciplina gastronómica conlleva unos nuevos elementos para el perfil profesional y para la reflexión pedagógica, y aunque explícitamente no se habla de un esquema de formación en gastronomía sí se puede inferir desde las dinámicas históricas y de registro de temas gastronómicos publicados.

\section{Posturas formativas frente a la gastronomía en el ámbito Iberoamericano}

Haciendo un rastreo documental de información relevante en el ámbito gastronómico frente al quehacer formativo se evidencia que, aunque no hay documentación explícita en torno a un esquema de la formación en gastronomía, se puede inferir de los distintos artículos publicados, por ejemplo, en el artículo "Tendencias gastronómicas predominante en la producción de revistas científicas de lberoamérica" (Hernández y otros, 2016) que se enfoca en describir las tendencias con el propósito de socavar las oportunidades para el ámbito investigativo gastronómico, también reflexiona en torno a si la gastronomía es una ciencia, un arte 
o una disciplina y delimita conceptos relacionados con tendencias y modas para resaltar la diferenciación entre tres ámbitos compatibles y complementarios, pero a la vez diferentes en la concepción de la gastronomía. A través de la revisión de 142 artículos publicados en revistas indexadas en Redalyc, Latindex y Scielo, describen las características de las tendencias predominantes en la producción científica de Iberoamérica. Este artículo se produce en Méxi$\mathrm{co}$, donde es evidente que se ha hecho un trabajo diligente en cuanto al reconocimiento, registro y enseñanza del ámbito gastronómico y alimentario, por tanto, no es de extrañar que las más diversas publicaciones sobre gastronomía sean de origen predominantemente mexicano frente al ámbito latinoamericano.

Para concluir su artículo (Hernández y otros, 2016) definen la gastronomía finalmente, como una disciplina, desde el ámbito formativo profesional, ya que se considera que tiene un objeto de estudio delimitado, que como se ha mencionado anteriormente, se refiere a la relación del hombre con el entorno, tomando como eje la alimentación, lo que también ha hecho posible su conceptualización, teorización y el surgimiento de nuevas carreras y orientaciones para la educación en este campo, incluso llegando a crearse programas que forman docentes de gastronomía, licenciaturas en gastronomías, de lo cual México es pionero en Latinoamérica. En este artículo también se reconoce el carácter multidisciplinar y polivalente del hecho alimentario y, por ende, de la gastronomía, incluso se llega afirmar que han sido más los aportes que han dado otras disciplinas a la gastronomía, que los que la gastronomía ha dado a otros saberes, sin embargo, esto no se debe específicamente a falta de contenidos o propuestas investigativas, sino a que, la labor gastronómica se redujo exclusivamente al ámbito culinario, no obstante, en los ámbitos investigativas han predominado los rastreos históricos, que han permitido una experimentación y un análisis crítico, así como, una innovación de las cocinas locales, que ha dado como resultado el surgimiento de ciertas tendencias gastronómicas, compartidas por un colectivo, una comunidad. De acuerdo con el texto hay tres tendencias que dominan el campo de producción científica en Iberoamérica, el regreso a las tradiciones y al patrimonio alimentario, la gastronomía ecosustentable $y$, finalmente, la ciencia en la cocina, predominando mayoritariamente, en la producción científica, los artículos relacionados con la identidad patrimonial alimentaria.

Con base en el análisis de los artículos publicados en revistas indizadas de lberoamérica seguirá predominando la tendencia regreso a lo básico. La actividad gastronómica forma parte del sector terciario -el relacionado con comercio, servicios, comunicaciones y transportes-, donde también se ubica el turismo. Por otro lado, se considera que en materia gastronómica lo que se demandará en los próximos años son investigaciones ambientales (ecológicas y sustentables), y en el terreno de la ciencia aplicada (experimentación culinaria de vanguardia) es un rubro incipiente en nuestro país, donde es un hecho que poco se invierte económicamente para el desarrollo y utilización de productos gastronómicos ecosustentables, así como en invenciones y patentes tecnológicas.

En relación con la formación profesional en la disciplina gastronómica en Instituciones de Educación Superior (IES), se vislumbra que la orientación predominante será la administrativa por su carácter eminentemente pragmático e instrumental. La ausencia o escasa producción científica en este campo permite respaldar esta afirmación. De este modo las carreras relacionadas con las ciencias económico-administrativas se visualizan como una orientación que predominan en la educación gastronómica (Hernández y otros, 2016, p. 83).

Para concluir, los autores sugieren como futuras líneas de investigación, reflexiones en torno a la conceptualización y teorización de la gastronomía desde los ámbitos de ciencia, arte y disciplina, este planteamiento también se introduce en el artículo de Salvador Melgar 


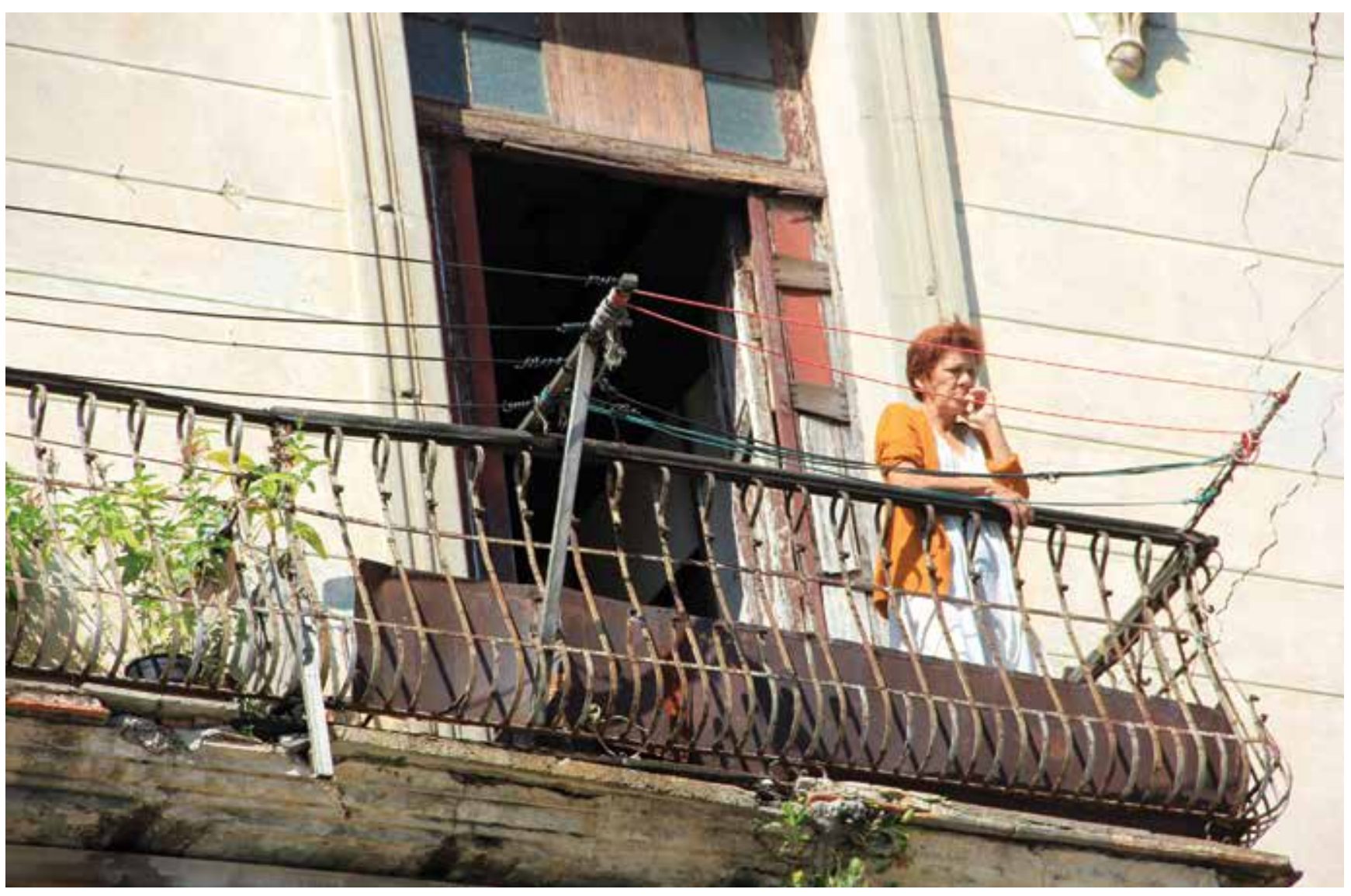

"La gastronomía en el sistema turístico. Buscando nuevos productos, mejorando destinos. El caso de la isla de Fuerteventura" en el cual se señalan perspectivas investigativas en torno a la relación gastronomía y su papel en el desarrollo local (2013), asuntos estos que han sido temas poco analizados y discutidos de forma estructurada y profesional, sin embargo, a esta reflexión se debería añadir también la producción reflexiva y discutida sobre la formación en la gastronomía, ya que al hacer un rastreo documental es realmente incipiente lo que se logra encontrar.

En cuanto a una postura frente a la formación en gastronomía lo que se pudo encontrar fueron artículos variados que, aunque no hacen una reflexión directa frente a este tópico, sí permiten explicitar algunas propuestas y estrategias de formación en el ámbito gastronómico.

Desde la propuesta formativa de los idiomas, se encontraron y analizaron, un artículo y un repositorio español y, una ponencia mexicana. La ponencia realizada en la ciudad de Tijuana, México por el docente (Vásquez, 1999) de la Universidad Autónoma de Baja California, consistió en exponer las necesidades laborales en contraste con la planeación lingüística detrás del currículo universitario.

La presente ponencia trata sobre del desarrollo curricular basado en las necesidades laborales. La Resolución 12 de la Conferencia General de 1999 de la UNESCO apunta hacia una educación multilingüe para poder satisfacer adecuadamente las necesidades culturales y lingüísticas de un mundo global y multinacional (p. 17). Instituciones de educación superior que ofertan licenciatura en gastronomía en el sector privado de la ciudad de Tijuana ofrecen francés como parte de sus requisitos curriculares, fenómeno relacionado a una larga tradición en el área, la técnica francesa clásica. El vocabulario especializado y muchas técnicas de cocina reciben su nombre en francés, en este fenómeno de préstamos lingüísticos radica motivo que sirve como 
locus para fundamentar los cursos de lenguas ofertados en programas de licenciatura en gastronomía en diversas universidades privadas de la ciudad de Tijuana. Sin embargo, no existen estudios de por medio que reflejen las necesidades lingüísticas en el campo laboral (evaluación de necesidades). La gran pregunta es entonces ¿es suficiente el prestigio histórico de una lengua en un área para fundamentar un curso o se necesitan tomar otros factores en cuenta al momento de desarrollar programas de lenguas con fines específicos? (Vásquez, 1999. p. 1).

A través de una serie de entrevistas aplicadas a licenciados en gastronomía y estudiantes de dicha licenciatura y a la revisión de planes de estudio se pretendió indagar sobre si la enseñanza del francés era una cuestión necesaria e imprescindible en el currículo de las licenciaturas en gastronomía, específicamente en la ciudad de Baja California, y aunque las conclusiones de este trabajo evidencian, que el idioma francés se enseña como una estrategia de prestigio y tradición en la disciplina gastronómica y, por ende, no es relevante en el contexto en el que se imparte, en este caso, la ciudad de Baja California, sí se evidencia a través de esta ponencia que la enseñanza de la gastronomía puede ser un agente motivador para aprender idiomas y contextos históricos y culturales diferentes.

A partir de las recomendaciones de la UNESCO (1996/2013) como producto del trabajo coordinado por Jaques Delors entre 1993 y 1996 que culmina en la obra La Educación encierra un tesoro, comienza un auge en la promoción del modelo constructivista, inspirando en las obras de Vygotsky y Piaget, quienes en rasgos generales plantean que la realidad es una construcción que parte de la vivencia, definida por la interacción social (ver Vygotsky, 1978) y también por el bagaje genético (ver Flavell, 1967). Esto significó para el modelo educativo mexicano hacer un paso de una educación basada en objetivos, a una educación basada en competencias (ver de la Cruz López, Rivadeneyra Castro, Trujillo Vázquez, 2013), y a su vez un replanteamiento de la estructura de la currícula, la cual se había estruc- turado tradicionalmente como un bloque de elementos incompatibles puestos en un mapa. Por otro lado, el nuevo paradigma educativo favorece una interconexión entre las materias, y de esta forma no se planea la currícula con una clase de español, aislada de una clase de etimologías y otra de literatura, y en cambio se incorporan en una sola materia llamada Lengua (de la Cruz López, Rivadeneyra Castro, Trujillo Vázquez, 2013). De esta forma se revalora el papel de cada área de conocimiento respecto a su utilidad (Vásquez, 1999, p. 3).

En el artículo de Catherine d' Humières, (2006) "La cultura del otro: español en Francia, francés en España", donde se recogen los contenidos presentados en el Encuentro Hispano - Francés de Investigadores (Sevilla, 2005) se hace un análisis frente a un tema predominante que ha marcado la tendencia en los libros utilizados, tanto en la enseñanza del francés en España como en la del español en Francia, que es la tendencia a unificar contenidos en torno a la gastronomía de un país, como un factor predominante en la identidad cultural, y aunque el artículo exalte esa función asociativa de la gastronomía con otros saberes desde la formación, también hace una crítica a la visión sesgada que dan estos libros de las costumbres alimenticias y propone:

Un doble análisis, sincrónico y diacrónico, de los capítulos dedicados a la comida en unos libros de texto españoles y franceses repartidos en dos periodos alejados de veinticinco años (1975 y 2000). Mi propósito es considerar, por un lado, lo que cada país privilegia en la gastronomía del otro, y de qué modo lo hace; $y$, por otro lado, qué visión del país extranjero -o de sí mismo- propone a los alumnos ( $d^{\prime}$ Humières, 2005. p. 1).

Para concluir su artículo, d' Humières afirma que en el análisis de los libros de texto reciente y desde el enfoque de la gastronomía como factor cultural de las naciones, se evidencian, no solo las dinámicas socio históricas, sino también, la transformación que ha vivido el contexto gastronómico español en contraposición al francés. 
Frente al repositorio realizado por la estudiante (López, 2016) de la Universidad Internacional de la Rioja, se puede evidenciar más explícitamente la propuesta de una estrategia didáctica en la enseñanza del español, desde el ámbito gastronómico, en este caso la enseñanza del español desde el ámbito de la gastronomía hispana, este repositorio hace referencia más a la práctica formativa, en cuanto propone un curso propiamente dicho, articulando la gastronomía hispana con la enseñanza del español.

En conclusión, la propuesta formativa que se da en los artículos y repositorios publicados desde la enseñanza de una segunda lengua propone; no explícitamente para el ámbito gastronómico, sino para la formación en idiomas, una visión holística de la enseñanza que integre distintos aspectos que estructuran una cultura en su totalidad y descartan, así, la tendencia de la enseñanza a fragmentar el conocimiento.

A nivel de primaria y secundaria surgen a través de artículos, congresos o reposiciones internacionales una serie de estrategias que dan prioridad a la enseñanza de hábitos adecuados de alimentación, no solo fundamentados desde la parte nutricional, sino desde "el diseño de unidades didácticas que contribuya a la educación alimentaria, gastronómica, y de los sentidos del alumnado de primaria, evidenciando que hay más conocimiento en el área gastronómica desde fuera" (Orgeret, 2016, p. 3), también desde distintos congresos hechos por el observatorio alimentario ODELA de la ciudad de Barcelona, y desde un enfoque cualitativo se han recogido memorias culinarias vividas por estudiantes, desde sus recuerdos gustativos, en este caso se recogen las experiencias de los estudiantes de un curso virtual de pedagogía en Brasil, articulándolo a la reflexión sobre el aprendizaje alimentario en las escuelas (I Congreso Internacional Comer en la Escuela, 2012). El propósito de este trabajo era evidenciar cómo las estrategias didácticas propuestas por los docentes, en un curso virtual, pueden hacer parte de una campaña alimentaria de divulgación en las escuelas, desde esta ponencia se exalta la labor de los cursos superiores virtuales dada su asequibilidad para las personas en general, ya que permiten una educación a distancia que plantea la posibilidad de que:

Los docentes y discentes puedan conocer un poco más de las culturas alimentarias más lejanas y también para divulgar las suyas, o mismo cambiar nuevas prácticas educacionales. Con intereses de sensibilizar a los estudiantes de un curso de pedagogía, sobre la importancia de las prácticas alimentarias para los conocimientos de la geografía y de la historia, fue ofrecido a ellos un fórum de discusión para escribieren las experiencias que tuvieran, en las escuelas, con las receptas e producciones alimentares, desde cuando eran chicos o mismo cómo maestros. Los textos, después de seleccionados, fueran divulgados en un sitio especial, un laboratorio virtual, donde todos los estudiantes de la universidad podrían coger nuevas propuestas lúdicas para sus prácticas profesionales (I Congreso Internacional Comer en la Escuela, 2012).

Desde las perspectivas formativas de los ámbitos alimentarios, sobre todo en lo que respecta al acondicionamiento de hábitos adecuados de alimentación, siempre hay un consenso sobre el carácter multidisciplinar de la gastronomía y como factor unificador de distintos saberes, y en las metodologías se privilegian las narrativas de la memoria, que se proponen como estrategias para identificar patrones culturales de grupos sociales que acogen unas $u$ otras tradiciones. Por lo tanto, en cuanto a la intencionalidad de estos textos, se propone que las prácticas pedagógicas desarrolladas por los docentes aboguen por privilegiar la memoria histórica (recuerdo) y la oralidad de los estudiantes, fomentando así campos de interés que articulen y fomenten un aprendizaje nuevo y útil desde los saberes previos.

Con respecto a las reflexiones pedagógicas en torno a la gastronomía, lo más cercano que se encontró en cuanto a publicaciones, fue un artículo realizado desde la página web, (Diario 
de Gastronomía, 2014), consolidada en España por un grupo de personas de distintas disciplinas, este artículo titulado, "La comida como herramienta pedagógica" (Diario de Gastronomía, 2014), da cuenta no solo de la carencia de reflexiones en torno a la utilización de la comida como herramienta pedagógica, sino que también recalca en el carácter nutricional, social, simbólico y celebratorio de la comida, lo que le atribuye una naturaleza unificadora y holística, a la hora de trasmitir un conocimiento sobre una realidad y contexto específicos.

También se logró observar de un repositorio en Cuba, una necesidad de elaborar...

un sistema de actividades que contribuyeran al reforzamiento del valor responsabilidad en los estudiantes que se forman como dependientes gastronómicos integrales para el logro de su desempeño laboral. En el proceso de la investigación, la autora revisó trabajos de destacados pedagogos que le permitieron realizar la fundamentación teórica de la investigación (Nápoles, 2010).

En este estudio se hizo un diagnóstico inicial frente a la visión que tenían los estudiantes con respecto al valor de la responsabilidad, esto debido a algunas dificultades disciplinarias presentadas en algunos momentos de la formación, sin embargo, las conclusiones del estudio arrojan, que la falta de responsabilidad obedece al desconocimiento que tienen los estudiantes frente a las políticas normativas y legislativas que conlleva el quehacer gastronómico y culinario.

Algunos académicos formados en turismo también han dado su aporte reflexivo a la práctica formativa del turismo desde la gastronomía, un ejemplo de esto se refleja en el libro de la docente Margarita Barreto (2005) de la Universidad de Caxias do Sul - Brasil, donde recoge los trabajos realizados por los estudiantes del ciclo superior de la carrera Licenciatura en Administración Hotelera de la Universidad Nacional de Quilmes (UNQ), Argentina.
Como anuncia el título, el libro trae recetas de la culinaria proveniente de las diferentes etnias que poblaron el sur del Gran Buenos Aires hasta los alrededores de La Plata, área de influencia de la UNQ. Pero la autora estimula a sus alumnos a investigar algo más que el origen de los platos. Los induce a rescatar el cotidiano de los diferentes grupos humanos que dan origen a la presente riqueza cultural. El resultado es una obra seria, profunda y, al mismo tiempo, de lectura fácil y agradable que lleva por historias que se parecen a las de la propia familia o a las de las familias de vecinos y amigos.

Desde el punto de vista pedagógico este libro demuestra la vigencia de las teorías de Montessori, pues es sabiendo encontrar el centro de interés de los alumnos que se los puede llevar a investigar. Muestra que, bien conducidos, los alumnos de grado son capaces de producir trabajos de contenido científico utilizando principalmente el método histórico, combinando adecuadamente técnicas de investigación como la entrevista, la observación participante y las historias de vida (Barreto, 2005).

Desde estas breves menciones de la entrevista, la observación participante, las historias de vida y el ejercicio de la memoria se pueden vislumbrar algunos esfuerzos por insertar estrategias metodológicas en la formación de los ámbitos gastronómicos. Otra propuesta interesante se evidencia en el artículo, el performance de lo yucateco: cocina, tecnología y gusto, que propone la técnica, en este caso contextualizada en la cultura yucateca, desde sus prácticas alimentarias. No se menciona explícitamente el performance como técnica de apropiación de conocimiento, pero si se puede inferir que a través de los estudios de cultural alimentaria, se perciben rituales de consumo que pueden ser útiles como estrategias de contextualización a la hora de enseñar sobre una cultura específica.

Este artículo examina cómo la elaboración de platillos yucatecos enfrenta una serie de niveles de performance que permiten la confirmación, para el sujeto y ante los demás, del desempeño como buen cocinero o cocinera, además de ser comida "auténticamente" yucateca (Ayora Díaz, 2014). 
El artículo concluye que los rituales del performance yucateco son complejos, y en este caso se concibe el término performance, como los rituales alimentarios de la cultura, en primer lugar, hace referencia a como la nación yucateca ha hecho de su cultura alimentaria una herramienta pedagógica, de arraigo cultural e identitario frente a la cultura mexicana en general, donde está enmarcada.

En este sentido, la cocina yucateca es representada en cuanto producto de una sensibilidad cultural propia de los yucatecos y distinta de lo mexicano, con fuentes en el Caribe y el resto del mundo. El performance culinario, por tanto, adquiere un papel fundamental en la afirmación de la identidad regional.

En segundo lugar, "lo yucateco" adquiere una dimensión performativa importante basada en la citacionalidad: las repeticiones tanto en el espacio doméstico como en el público de los restaurantes introducen diferencias que reflejan la apropiación de ingredientes, técnicas y tecnologías que eran, hasta hace poco, ajenos a las prácticas culinario-gastronómicas locales que los mediadores culturales gustan de presentar como estáticas (Ayora, 2014).

Finalmente se concluye que el performance culinario y gastronómico yucateco se establece como un ejercicio de poética y memoria viva de la identidad política cultural, sin embargo, se aclara el carácter de un performance que no ha estado ajeno a los procesos interculturales y de mestizaje, y es en esta estrategia múltiple de lo pedagógico y lo performativo que se da el espacio para que aparezcan fusiones gastronómicas o culinarias en búsqueda de una reivindicación.

Es en este contexto, que el estudio del performance culinario-gastronómico, como sitio de articulación de distintas dimensiones del sentido cultural, permite una mayor y mejor comprensión de las complejidades sociales y político-culturales que se expresan en la elaboración cotidiana de los alimentos y complementa otros espacios del performance público y privado (Ayora, 2014).
Se podría decir después de varios rastreos y análisis documentales, que es desde las facultades de educación y sus repositorios donde se enmarca cada vez más una tendencia a educar en la cultura, desde las prácticas alimentarias. Sin embargo, hay proliferación documental a este respecto en países latinoamericanos de marcadas tendencias indigenistas, como son México, Perú y Guatemala, un ejemplo de esto, es el repositorio de la estudiante Irma Hiliana Cifuentes Paul de Ramírez (2012) que, desde la Facultad de Educación en la Universidad del Istmo en Guatemala, propone en este caso, una guía metodológica utilizada en un curso de gastronómica nacional guatemalteca, con el objetivo de reivindicar la identidad nacional y la virtud del patriotismo.

A nivel nacional varias escuelas culinarias están abriendo espacios para rescatar los saberes y valores culturales de la Gastronomía Guatemalteca e incluirlos al Sistema Educativo Nacional, para reivindicar la cultura de los pueblos indígenas.

Gracias a grandes luchas y sacrificios realizados por instituciones y el pueblo maya, se ha logrado que el Estado guatemalteco reconozca legal y políticamente la necesidad de reivindicar desde el campo educativo la cultura propia de los pueblos que coexisten en el país (Cifuentes, 2012, p. 11).

Por lo mismo es urgente que los establecimientos educativos promuevan las prácticas culinarias ancestrales pues en la actualidad se les da prioridad a prácticas que a culturalizan a las alumnas en vez de fortalecer su identidad; en otras palabras, se les asigna gran valor a otras preparaciones y se desvaloriza lo propio (Cifuentes, 2012, p. 12).

Esta investigación nació de la necesidad de fomentar en unas alumnas de gastronomía el sentimiento de arraigo y pertenencia cultural, ya que generalmente en las disciplinas gastronómicas predomina la enseñanza de preparaciones o técnicas estandarizadas y de índole globalizado que poco o nada reflejan las tradi- 
ciones ancestrales de los países donde se imparte la disciplina.

Otro artefacto muy provechoso para entender las dinámicas pedagógicas de la enseñanza de la culinaria en el mundo, son los manuales de buenas maneras, higiene y culinaria que proliferaron a principios del siglo XX, tal es el caso de un artículo argentino de la revista Temas de Mujeres, que analiza uno de estos manuales. En este artículo se expone la carencia que hubo en el contexto argentino en torno a las investigaciones históricas del ámbito alimentario, en contraste con la sociología y la antropología, como disciplina pionera en las investigaciones referentes a los ámbitos alimentarios culturales y adaptativos, sin embargo, en la década del setenta se introdujeron en el campo historiográfico argentino nuevos temas, problemas, enfoques y objetos, entre los que se hallaban la cocina y las mujeres, que es el caso que atañe a este artículo.

Reflexiona sobre cómo ha sido el estudio histórico en torno a la mujer y su rol, basándose en:

Libro del pedagogo Angel Bassi publicado en 1914, Gobierno, Administración e Higiene del Hogar. Curso de Ciencia Doméstica. Un texto destinado a las/os docentes de área en cuestión tanto de escuelas primarias como de las secundarias, en cuyo contenido se destacan los capítulos orientados a la transmisión del saber culinario (Caldo, 2009, p. 33).

El propósito de este artículo fue hacer un cuestionamiento frente a los sentidos de la enseñanza de la cocina a las mujeres en las escuelas argentinas, a principios del siglo XX. Interrogantes como:

¿Qué saberes comprendió la materia Cocina? ¿Por qué enseñar a cocinar a las niñas en las escuelas? ¿Bajo qué condiciones y presupuestos? ¿Qué platos se proponían? ¿Con qué medios, técnicas, utensilios se resolvían las recetas? ¿En qué tiempos? ¿Quiénes consumirían los resultados de aquellas prácticas?... Preguntas, cuyas respuestas no las hallaremos en el orden de las prácticas concretas sino en el propio de un artefacto textual generado para el logro de la transmisión escrita del saber culinario (Caldo, 2009, p. 33).

Cuestionamientos que pretende comprender a través del libro anteriormente mencionado, del pedagogo Angel Bassi (1914). “Un texto destinado a las/os docentes de área en cuestión tanto de escuelas primarias como de las secundarias, en cuyo contenido se destacan los capítulos orientados a la transmisión del saber culinario" (Caldo, 2009, p. 33).

El punto de intersección, donde se juntan mujeres y cocina, se halla atiborrado de nudos problemáticos entre los que hemos acordado rescatar uno, el propio de la transmisión del saber culinario a las mujeres en un espacio y en un tiempo en particular, las escuelas argentinas en la década de 1910. Los por qué, qué y cómo de tal hecho educativo los responderemos a partir de la lectura interpretativa de la obra del, ya citado, Angel Bassi. Un pedagogo que, entre los años 1894 y 1920, se ocupó de la educación de las mujeres. Tal interés cristalizó en las páginas de un libro que hoy nos sirve como fuente para reflexionar alrededor del semblante que la pedagogía argentina, cierta vez, atribuyó a la cocina y de las cocineras (Caldo, 2009, pp. 34-35).

En un momento histórico en el cual la cocinagastronomía se distanciaba de la dietética y buscaba el placer, las mujeres-amas de casa fueron orientadas para derrocar tal separación, al menos en sus prácticas cotidianas y privadas. En tal sentido, la dicotomía público-masculino versus privado- femenino también afectó al ámbito de las prácticas culinarias. Así, Angel Bassi escribió una propuesta pedagógica para intervenir sobre la subjetividad femenina a los efectos de hacer de las pequeñas niñas, futuras amas de casa. Tarea que, lejos de ser ingenua, pretendía hacer de las mujeres piezas óptimas que operaran en el cuerpo socio político del momento. Entonces, desde la más tierna infancia, entre otras cosas, las niñas aprenderían el arte de cocinar. Una cocina que se asoció no con el placer sino con una gramática culinaria vigilada por el ojo de la 


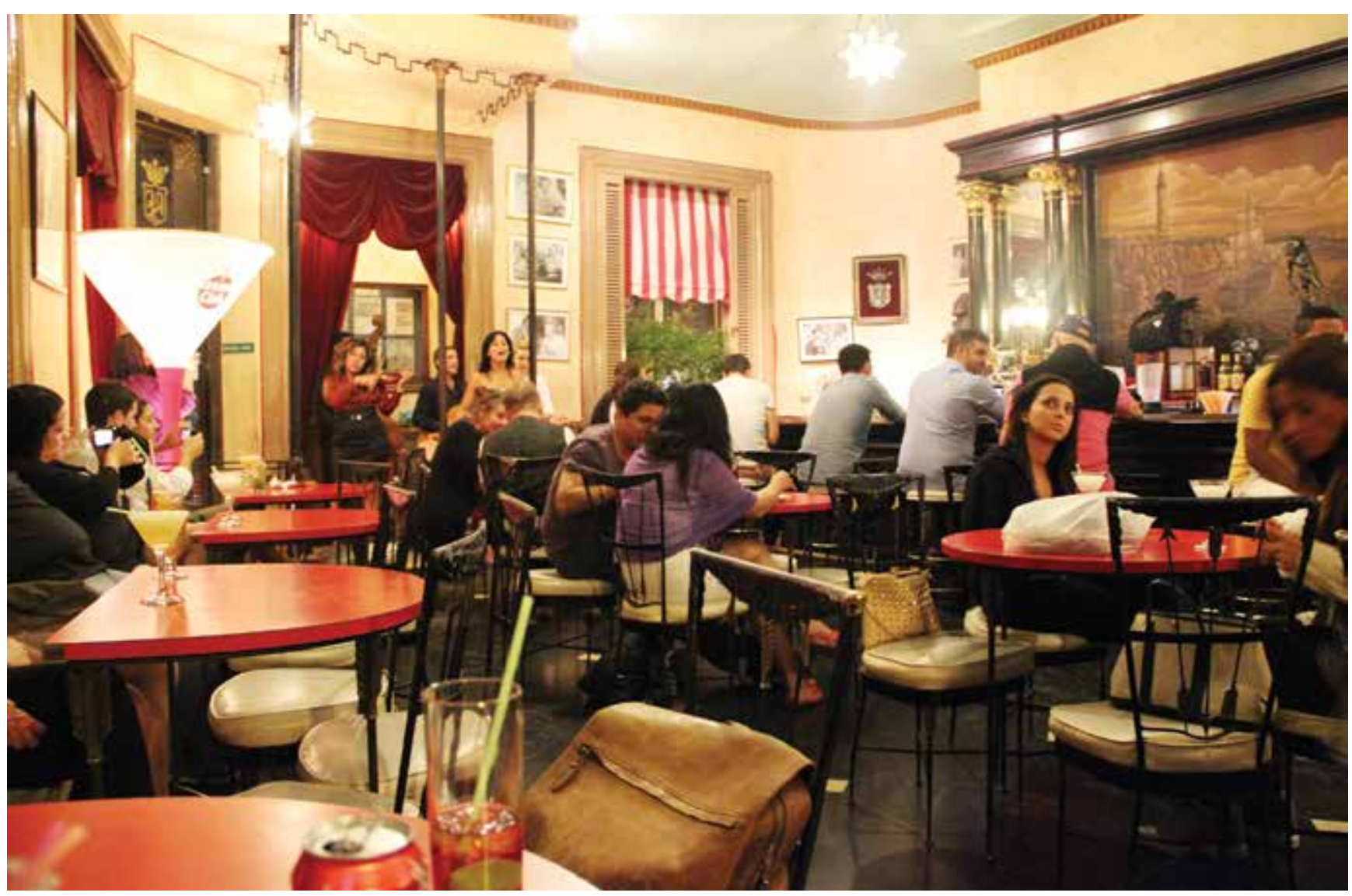

medicina higienista. Las cocineritas de Bassi desplegarían su saber con miras a lograr la salud, el buen comportamiento y la higiene de su prole.

En las páginas del libro de nuestro pedagogo la alimentación se revela como un hecho crucial para la formación de sujetos física y psíquicamente sanos. Y, en esta acometida, sobre el cuerpo y la sensibilidad femenina reposó la responsabilidad de cocinar para el cumplimiento de tal objetivo. Entonces, desde pequeñas, en las aulas, las niñas debían aprender la composición de los alimentos, las combinaciones más sanas y digeribles para el organismo como así también las más acordes a la economía familiar -lecciones de ahorro-. El desafió, aunque rigiendo sobre una de las prácticas más cotidianas y nimias del hogar, apuntaba a cosechar sus frutos en la sociedad en general. Al escribir sus preceptos, Bassi parecía suponer que, cocinar hace a los seres humanos, y éstos a la sociedad toda... Sentencia que sitúa a las mujeres-cocineras amas de casa como un engranaje clave de las políticas socioculturales de la época (Caldo, 2009, p. 47).
Desde la perspectiva de este artículo y en el análisis del libro de Bassi, se cuestiona implícitamente el rol de la mujer en la sociedad argentina del principio del siglo $\mathrm{XX}$, tomando como referente el ámbito culinario; un espacio que, en los discursos de los roles de género, casi siempre ha pertenecido a la mujer, sin embargo, y cabe aclarar en el análisis al texto de Bassi, que no existe ninguna pretensión machista y que de hecho, por lo que se aboga, es por el mejoramiento de la alimentación y nutrición a través de la formación a mujeres en asuntos culinarios, ya que desde el contexto de principios del siglo XX, la mujer es quien se encarga de perpetuar la cotidianidad cultural. Ahora bien, si sacáramos el contexto histórico donde se desarrolla el manual de Bassi y el rol de la mujer de dicha época, podría llegar a ser una estrategia acertada, proponer asignaturas en la educación básica (independientes del género) que aborden cuestiones como, la culinaria, la nutrición, la salud y los alimentos, no solo como 
enseñanza de un saber hacer, sino con el propósito de reflexionar y perpetuar unas buenas practicas alimentarias.

En cuanto a los enfoques educativos que se proponen recientemente, predomina una tendencia de enseñanza colaborativa que, desde una reflexión pedagógica de la disciplina gastronómica y su interdisciplinariedad, debe analizarse y evaluarse, como uno de los enfoques que se podrían implementar en la construcción del discurso pedagógico en torno a la disciplina gastronómica y culinaria. Desde la ponencia de la docente Natalia Santos Orozco (2013), La enseñanza colaborativa (team teaching) como método para una educación integral: La experiencia del curso Los sabores de la escritura: Cultura gastronómica y literatura en Hispanoamérica (Santos, 2013), se aborda el tema de la enseñanza colaborativa, no como un enfoque propiamente dicho para la gastronomía, sino como un modelo diagnóstico y evaluativo en la enseñanza de un curso específico, en este caso, un curso que relaciona la literatura hispanoamericana y la gastronomía, y que aboga por un enfoque integral y colaborativo de enseñanza.

En esta ponencia se socializa con la comunidad académica la experiencia de dos docentes en cuanto a la aplicación del enfoque de enseñanza colaborativo en el curso Los sabores de la escritura: Cultura gastronómica y literatura en Hispanoamérica, que se impartió en la Escuela de Administración de Hoteles y Restaurantes de la Universidad de Puerto Rico en la ciudad de Carolina, entre el 2012 y el 2013.

El Programa de Estudios de Honor de la UPR en Carolina ha creado un plan curricular que contempla, como parte de sus objetivos generales, el desarrollo del pensamiento transdisciplinario mediante el ofrecimiento de cursos interdisciplinarios que expandan los límites del plan de estudio de los y las estudiantes del Programa. Recientemente, se comenzó a implantar una oferta de cursos interdisciplinarios de enseñanza en equipo o team teaching, medida que se fundamenta en el reconocimiento de su idoneidad en el contexto de la educación universitaria en general y, específicamente, en los beneficios que este método pedagógico aporta a la consecución de los objetivos del Programa (Santos, 2013, p. 1).

Frente al concepto de team teching o enseñanza colaborativa, la ponente aclara que el término:

Se utilizó y se ha utilizado para nombrar diferentes tipos de prácticas y enfoques educativos y; el desarrollo del uso de los diversos modelos en el sistema educativo estadounidense está directamente vinculado con la solución de problemas administrativos y de organización escolar concretos (Santos, 2013, p. 3).

En conclusión y desde la experiencia de la aplicación de este enfoque, las docentes constatan que hay más ventajas que desventajas frente al logro de aprendizajes y objetivos, sin embargo, dado que es una propuesta "reciente" y que confronta el paradigma actual de enseñanza, donde el cocimiento es trasmitido fragmentadamente, requiere de nuevas reformulaciones para ser implantado, entre ellas, capacitaciones a los docentes y estudiantes sobre la fundamentación de este nuevo modelo. En cuanto a las ventajas y a modo de conclusión:

Como hemos podido apreciar, las ventajas que se obtienen del modelo interdisciplinario de enseñanza en equipo son significativas y superan las desventajas. Constatamos que se potencia la consecución de objetivos y el desarrollo de destrezas fundamentales que difícilmente se atienden en cursos tradicionales. El modelo facilita el desarrollo de una educación plena desde una perspectiva educativa integral. No obstante, convendría el desarrollo de programas de capacitación dirigidos a la formación de la facultad y la formulación de normativa que contemple y regule la implantación de modelos de enseñanza en equipo. Por último, de acuerdo a la experiencia reseñada, es imprescindible contar con una política institucional que facilite y apoye la innovación en la enseñanza con el fin de atender, desde una perspectiva universitaria, los retos que los nuevos tiempos nos imponen (Santos, 2013, p. 10). 
En la búsqueda documental sobre los posibles discursos que se han tejido en torno a la reflexión pedagógica en la disciplina gastronómica, predomina la producción de artículos brasileños. Desde un análisis documental y en orden cronológico de algunas bases de datos en la web, se encontró el repositorio o disertación de la estudiante María Cristina Pinto de Menezes (2005) desde el Centro Universitario Nove de Julho-Uninove en Sao Pablo, cuyo propósito era realizar un estudio cualitativo sobre el proceso de formación en un curso superior de gastronomía en la ciudad de Sao Paulo, donde se analizó cómo se daba esa formación tomando en cuenta al estudiante como ciudadano, y cómo este construye su identidad cuando confronta la fuerza laboral en la cual se quiere desempeñar. Este estudio se hizo basado en las percepciones y representaciones que tienen los estudiantes sobre la escuela, sus condiciones de vida y sus historias de vida y, finalmente, concluye que la mayoría de los estudiantes investigados vienen de niveles medios de la sociedad, que tienen una visión idealista sobre el entorno laboral de la gastronomía y que su interés por el estudio de esta disciplina viene ligado a la historia de vida, también se evidenció que la identidad profesional del gastrónomo en este contexto se construye a raíz de expectativas generadas en los medios que son poco realistas frente al ámbito laboral de la gastronomía y también, que dicha identidad se pretende moldear desde la incorporación de ámbitos altamente competitivos, destacándose el ámbito del emprendimiento.

Otro repositorio que se pudo encontrar en las bases de datos y analizar, también proviene del mismo programa de educación, de la Universidad Nove de Julho de Sao Paulo y se titula: "Entre panelas, livros e tradições: as trajetórias de formação do professor de gastronomía" de Beatriz de Carvalho Pinto (2010). En esta investigación, diez años posterior a la analizada anteriormente, se propuso hacer una reflexión sobre la formación de los docentes de gastro- nomía en la ciudad de Sao Paulo, una ciudad que reconoce la autora, requería, debido a sus dinámicas alimentarias de índole migratorio donde la gastronomía es muy diversificada, un análisis crítico en torno a la formación de los educadores de los programas de gastronomía, es decir, un análisis de la formación que tome en cuenta la pluralidad de la ciudad y que evidencie el compromiso que tienen los docentes del ámbito gastronómico y culinario, independiente de su nivel de formación, de educarse en pedagogía, para así dirigir sus estrategias de enseñanza, más allá del esquema conductual y mecánico predominante en la formación de la gastronomía y la culinaria.

En cuanto a la producción de artículos que aborden el tema de la pedagogía en la disciplina gastronómica en el contexto brasileño, está el artículo de la gastrónoma Amanda Oliveira Magalhães ( 2011), titulado: "A formação do professor nos cursos de gastronomía: reflexões transdisciplinares", que hace una problematización de la formación docente de los profesores de las carreras gastronómicas y culinarias, reflejando que hay una emergencia por una formación y una praxis pedagógica que permita la construcción de una educación transdisciplinar en el campo de la formación gastronómica. La corriente sugerida por la autora, es la de la educación liberadora del pedagogo Paulo Freire que propone una nueva condición social del individuo, concibiéndolo como un ser pensante, reflexivo y crítico del contexto que lo rodea.

En relación con el análisis de la documentación que da cuenta de una postura formativa frente a la disciplina gastronómica o culinaria en el contexto brasileño, se evidencia que el factor común para la producción de dichas reflexiones es consecuencia del carácter informal que se le ha dado a la enseñanza de la gastronomía y a la carencia de conocimientos y estrategias pedagógicas de los docentes de gastronomía o culinaria. La estrategia para sopesar esta carencia, es abordada desde el artículo de Oliveira Magalhães (2011) con una propuesta 
de enfoque transdisciplinar, donde el proceso de enseñanza-aprendizaje de la gastronomía sea dinámico, coherente, significativo y complementado desde otros saberes, en suma, que sea integral.

Es evidente que uno de los países latinoamericanos que más ha incorporado el discurso reflexivo sobre la praxis pedagógica en la gastronomía ha sido Brasil, y no es de extrañar, dada la tradición de reflexiones formativas que han surgido allí. En el artículo de Sperandio (2015) "A formação superior em gastronomia: análise descritiva das dissertações de mestrado produzidas no Brasil" para la Revista Brasilera de Pesquisa em Turismo se da a conocer el panorama de las investigaciones realizadas en Brasil en posgrados en torno a la formación profesional en gastronomía.

Se hizo una revisión de la bibliografía, investigación documental y análisis descriptivo de las tesis leídas en Brasil hasta el final del 2012. Se han analizado: las instituciones de enseñanza y los programas de posgrado; las palabras-clave enseñadas; el perfil de los investigadores (formación y experiencia profesional); objetivos generales y el alcance de las investigaciones, bien como la metodología empleada. Los principales resultados se refieren a: el predominio de investigaciones llevadas a cabo en la ciudad de São Paulo, investigadores familiarizados con la formación técnica en gastronomía (desde un punto de vista de la formación y actuación profesional), predominio de temas orientados a un proceso de enseñanza-aprendizaje, prevalencia de investigaciones de carácter cualitativo y la ocurrencia de descripciones muy breves de la metodología empleada en algunos estudios (Sperandio, 2015, p. 157).

Otra de las cuestiones que se refleja a través de la documentación producida en Brasil sobre el proceso de enseñanza-aprendizaje en gastronomía, son las reflexiones referentes al perfil profesional y su articulación con la formación. Cabe destacar que, en Latinoamérica, los programas de gastronomía y culinaria nacen como una propuesta de formación para el trabajo.
En el análisis de Sperandio (2015) se concluye finalmente que, en Brasil y en cuanto a su producción de tesis de maestría en torno al proceso de formación en la disciplina gastronómica, la mayoría de investigaciones se realizaron en la ciudad de Sao Paulo y que quienes hicieron dichas investigaciones tienen alguna vinculación con los programas de gastronomía y formación. Según Sperandio, hay una gran valoración por las propuestas de reflexión referentes al proceso de enseñanza-aprendizaje en gastronomía, sin embargo, son propuestas que casi siempre se enmarcan en el contexto de formación para el trabajo.

Aunque en Brasil no se ha generado una teoría propiamente dicha sobre cómo debe estructurarse el proceso de enseñanza-aprendizaje en la disciplina gastronómica, sí se pueden evidenciar algunas propuestas de estudios de casos (descriptivos) y una gran inquietud por formar educadores dentro del ámbito disciplinar de la gastronomía, dada su demanda actual.

Entre las bases de datos, también resalta el artículo de la revista: Estudios y Perspectivas en Turismo de Donato M. Dreher y Zuleica Maria (2003), docentes de la Universidad Federal Santa Catarina en la ciudad de Florianópolis que, desde una perspectiva turística, ya que el contexto donde se realiza la investigación tiene esta característica, busca "conocer las opiniones que los trabajadores gastronómicos de la ciudad de Florianópolis, capital del Estado de Santa Catarina, Brasil tienen sobre su calidad de vida" (Dreher y Maria, 2003, p. 290).

El trabajo de campo consistió en entrevistas semi-estructuradas que fueron analizadas mediante la técnica de reflexión síntesis. El marco teórico focaliza en la calidad de vida, el turismo, la cultura y la gastronomía. Describe la realidad cotidiana del ramo gastronómico asociándolo al turismo y la actividad cultural de la ciudad. Los temas que surgieron van desde el proceso de construcción individual de la profesión hasta el concepto de "turista inteligente", identificando al turismo gastronómico como promotor de la 
valorización de la identidad cultural de la región, incentivando el mantenimiento de sus sistemas productivos e estimulando mejores condiciones socioeconómicas para las poblaciones originales lo que contribuye a la calidad de vida individual y colectiva (Dreher y Maria, 2003, p. 290).

Aunque específicamente no es un artículo que hable de formación en gastronomía, sí es un buen estudio de partida para analizar cómo están siendo concebidos el perfil laboral y los cocineros vs gastrónomos desde su formación, en el contexto actual latinoamericano, de modo que sirva para aclarar algunas cuestiones en torno a la concepción y los objetos de conocimiento de la disciplina gastronómica vs la culinaria.

Un aspecto relevante que se analiza en la investigación de Dreher y Maria (2003) es la importancia de la gastronomía para el turismo.

Se observa que continuamente crece el número de personas que visitan determinadas regiones en especial para saborear platos tradicionales. El turismo gastronómico se puede caracterizar como "ecológicamente correcto". Buscando preservar el ambiente cultural también ha colaborado para valorar la identidad de ciertas regiones incentivando el mantenimiento de sus sistemas productivos y promoviendo mejores condiciones socioeconómicas para las poblaciones nativas, lo que contribuye a mejorar la calidad de vida individual y colectiva.

Se debe reflexionar más sobre la importancia de la gastronomía para nuestra calidad de vida y el papel del profesional del área en ese contexto. Su calidad de vida, su formación profesional y personal, su estado de bienestar como individuo-ciudadano, su ambiente de trabajo, etc. En especial es importante que los clientes conozcan el significado que tiene el trabajo para esos profesionales, aquellos que preparan y que sirven el alimento, ya que, si para ellos el alimento es sagrado, posiblemente estarán colaborando en promocionar una calidad de vida más saludable (Dreher y Patricio, 2003, p. 308).

Este análisis también se puede estructurar como una de las tantas propuestas que ofrece la disciplina turística a la gastronomía con respecto a la unión y el diálogo de sus contenidos. Generalmente ha sido la disciplina turística quien le ha planteado la discusión a la formación gastronómica e incluso en los currículos de la mayoría de programas de formación latinoamericanos, se evidencia una articulación al turismo.

Otro aspecto relevante que se puede evidenciar en algunos artículos gastronómicos de las bases de datos es el surgimiento de nuevas corrientes alimentarias y culinarias en contraposición a la aceleración y devastación del mundo actual, tal es el caso del artículo de Campolina y Souza Machado (2015) "Gastronomia sustentável, formação do gastrônomo e desenvolvimento local" para la revista Competencia de Porto Alegre, en el que se hace énfasis en el diálogo entre la sustentabilidad y la gastronomía en la formación profesional del gastrónomo. El artículo finaliza resaltando la importancia que tiene la interdisciplinariedad en la formación gastronómica y los retos pedagógicos que esto implica.

En el rastreo documental también se evidencia que el arte ha planteado algunas posturas con relación a la gastronomía; a propósito de esta temática, se encuentra el artículo de Berta Garrido Moreno (2012), "La cocina y la experiencia culinaria como proceso artístico y creativo", publicado en la revista Creatividad y Sociedad.

Este artículo revisa los límites y confluencias entre el arte y la gastronomía y la posible consideración de esta última, como categoría artística. Tomando como punto de partida la polémica inclusión de un cocinero -Ferran Adrià- en una Feria Internacional de Arte "La Documenta de Kassel en 2007" y las diferentes teorías tanto curatoriales como filosóficas que avalan, secundan y discuten tal cuestión (Garrido, 2012, p. 1).

En el análisis de Garrido (2012) se puede observar un rastreo histórico sobre las distintas representaciones que ha tenido la gastronomía y la culinaria desde el arte, se enfoca especial- 
mente en los últimos años cuando, según ella, surge el cuestionamiento en torno al carácter creativo y artístico de la cocina y la culinaria, partiendo del momento en que la concepción alimentaria del nutrirse se desligó de la acción de degustar, lo que daría como consecuencia, la creación de una disciplina gastronómica.

En La esencia del estilo (2008), un reconocido estudio en torno al origen del lujo y el glamour en Francia a partir del reinado de Luis XIV, la historiadora francesa Joan Dejean acota cronológicamente el surgimiento de tal distinción. En sus palabras: Durante la segunda mitad del siglo XVII comenzó a explorarse una nueva ciencia que mucho más tarde se llamaría gastronomía. Como resultado de este proceso, cocinar y comer dejaron de considerarse una simple necesidad para convertirse en un terreno donde la sofisticación resultaba posible y deseable (Dejean, 2000, p. 101) (Garrido, 2012, pp. 5-6).

De acuerdo con Garrido Moreno (2012), la discusión en torno a la gastronomía como arte:

Se da en la actualidad porque existe una confluencia de pensamiento en tres disciplinas diferentes; la Filosofía, el Arte y la Gastronomía. En primer lugar, el pensamiento contemporáneo ha reabierto el debate en torno a la jerarquización de los sentidos. Pensadores como Carolyn Korsmeyer o Michel Onfray, plantean de modo riguroso el desprestigio que han sufrido los sentidos desde la Antigüedad. Estas clasificaciones distinguieron algunos sentidos como inferiores como en el caso del gusto. Lo que Onfray o Korsmeyer consideran es la reivindicación del gusto como un sentido digno del estudio y la teorización de la percepción del mundo sensible a través de éste, añadiéndole un valor estético que reconozca el papel representativo y expresivo de la comida dentro del discurso del arte.

Por otra parte, la cocina en las últimas décadas ha sufrido una gran revolución que ha derivado en la aceptación de un nuevo término y de un nuevo concepto o modo de entendimiento de las manifestaciones gastronómicas: la llamada cocina tecnoemocional. Este tipo de cocina conlleva, según la propia definición y concepción teórica que Ferran Adrià y su equipo realizan, la inclusión del intelecto de una forma intencionada por parte de un cocinero. De este modo, el acto de comer ya no se concibe simplemente como algo necesario para la supervivencia y la nutrición del individuo sino como una experiencia que además de agradar al sentido agrada al intelecto (Garrido, 2012, pp. 33-34).

Este artículo de Garrido (2012) está justificado en el análisis que hizo la autora de un acontecimiento de gran relevancia para el reconocimiento del ámbito gastronómico desde el punto de vista artístico, que fue la inclusión del cocinero Ferran Adrià en la Documenta de Kassel en 2007, uno de los festivales de arte más importantes del mundo, según la autora esta inclusión fue un tema polémico que planteó el debate sobre el reconocimiento de la gastronomía como arte o la legitimación del cocinero como artista, sin embargo, concluye que son la producción y la experiencia gastronómica las que se pueden considerar arte, siempre que respondan a las lógicas propias de esta materia. Predice la autora que al igual que la cocina y el consumo sufrieron transformaciones en cuanto a una distinción disciplinar, es probable que la evolución resalte aquellas creaciones gastronómicas de índole artístico, dando lugar a una fusión de discursos que deriven en una materia de gastronomía artística propiamente dicha.

Otro artículo que hace un acercamiento al concepto de gastronomía como arte, es el de la investigadora Ana María Zalles Iturri (2015), titulado: "Primera aproximación a una fundamentación teórica de la gastronomía como arte" y publicado en la revista virtual especializada en gastronomía: CULINARIA, de la Universidad Autónoma de México, que analiza cómo el concepto de arte ha ido evolucionando hasta la posibilidad de que nuevas actividades y propuestas se consideren arte, concediéndole a este concepto:

Una cualidad dinámica, en constante transformación, inmersa además en los medios de comunicación de masas, en los canales de consumo, con un aspecto muchas veces efímero, 


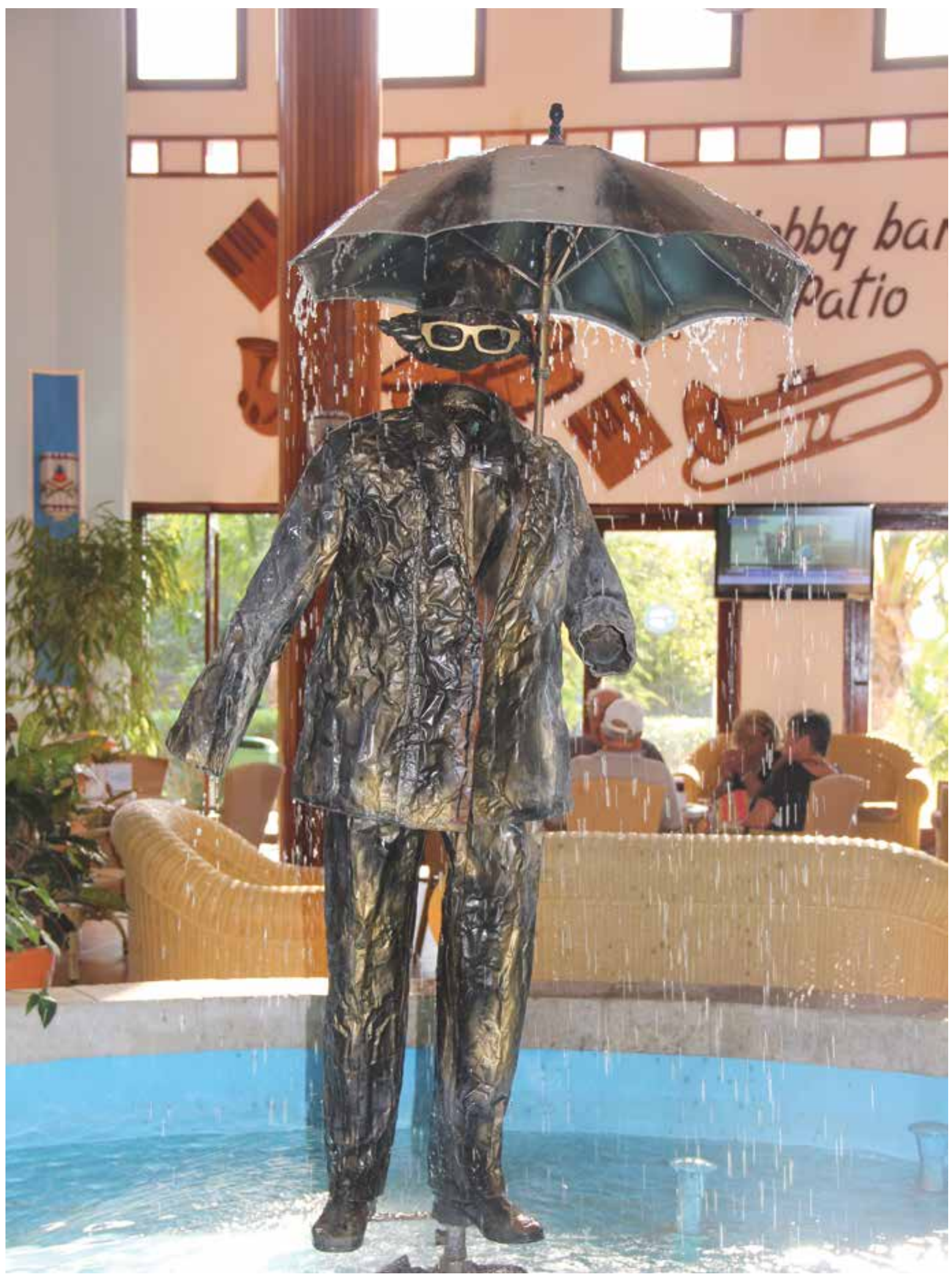


de percepción instantánea, presente con igual validez en la idea y en el objeto, en su génesis conceptual y en su realización material (Zalles, 2015).

También afirma la autora, esa necesidad que tiene cada arte nuevo de construir una justificación teórica y un respaldo filosófico, en este caso el análisis de la gastronomía, como un arte, que puede ser retomado por la disciplina gastronómica para generar un discurso en sí misma desde fundamentos ontológicos, epistemológicos y metodológicos donde se exalte una formación de y en los sentidos.

Otra apuesta curricular que se puede extraer de las bases de datos, es el papel que el periodismo gastronómico en Internet puede desempañar como función didáctica, se trata de la ponencia del docente Fernando Sánchez Gómez (2010), titulada "La función didáctica del periodismo gastronómico en Internet" y presentada en el marco del Congreso de Alfabetización Mediática y Culturas Digitales en la Universidad de Sevilla.

Internet y la Web 2.0 universalizan la educomunicación (García Galindo, 1999) culinaria mediante páginas web temáticas y gastroblogs con nuevas estrategias pedagógicas y participativas (Pérez Tornero 2005). El Periodismo Gastronómico nace en la Francia del XIX para instruir ciudadanos en el arte de comer y de recibir invitados. Llega a España en 1976 con idéntica vocación didáctica, cuando cocineros y comunicadores gastronómicos crean el boom mediático de las Nuevas Cocinas (Sánchez, 2010). Esta comunicación muestra su evolución hasta llegar a los medios digitales que difunden las novedosas técnicas culinarias, enseñan a los lectores/consumidores (Sánchez, 2010).

Desde este análisis del contexto histórico del periodismo gastronómico español y de su función pedagógica, se podrían consolidar puntos de partida en torno a estrategias de mediación digital para la enseñanza y socialización de temáticas gastronómicas desde un enfoque periodístico, así como proponer la inclusión de contenidos disciplinarios del periodismo y la comunicación en los programas de formación gastronómica en general, que promuevan una formación de la gastronomía enmarcada en la era digital actual y de carácter más incluyente.

En Internet se ha creado en los últimos años un espacio muy importante para la difusión de la comunicación gastronómica que no pasa por las páginas electrónicas de los diarios. La opinión gastronómica en la Red tampoco es competencia exclusiva de los medios de comunicación, porque cualquiera puede dar su opinión particular de un restaurante en el espacio que las publicaciones electrónicas habilitan para ello (Sánchez, 2010).

De este análisis de ponencias, artículos de revistas indexadas, artículos de prensa y repositorios iberoamericanos y de las posturas que exponen o se proponen en torno a la formación en gastronomía, se podría afirmar que hay poca producción frente a la temática, sin embargo, desde estas posturas sería posible comenzar a consolidar un discurso de reflexión pedagógica frente a la formación en gastronomía desde sus contextos, contenidos, enfoques, metodologías, estrategias, objetos de conocimiento y potencialidades.

\section{Posturas formativas frente a la gastronomía en el ámbito colombiano}

Actualmente en el país hay un interés creciente por el fenómeno gastronómico, sin embargo, en los rastreos documentales y en entrevistas con miembros del gremio gastronómico, y con docentes y estudiantes se evidencia un desconocimiento general sobre lo que conlleva una disciplina gastronómica vs estudiar cocina o culinaria. En el contexto colombiano, y aun cuando ya existen programas dedicados exclusivamente a la profesionalización en gastronomía, todavía falta claridad frente a la concepción, la teorización, los objetos de estudio y los campos de desempeño de la gastronomía profesional. En este país la disciplina gastronómica es aun concebida para la formación 
de un chef o un cocinero, dado que cuando se empezó a impartir culinaria en Colombia bajo denominación del término gastronomía, se buscaba era una formación que diera competencias para el trabajo, es desde este tipo de formación que se replantea la culinaria como una carrera profesional en el marco disciplinar gastronómico, que es al menos lo que en teoría sugieren algunos programas profesionales, sin embargo, cuando se analizan los currículos de dichos programas, las diferencias que se observan frente a las técnicas o tecnologías culinarias o gastronómicas, es que predominan los enfoques interdisciplinarios dependiendo de la facultad o el tipo de universidad y se privilegian los cursos orientados a investigaciones e innovaciones gastronómicas, no obstante, cuando se confronta este nuevo estatus de profesional con los estudiantes y docentes, se percibe que las carreras profesionales en gastronomía terminan siendo solo una extensión de técnicas y tecnologías que lo único que enseñan son los mismos contenidos de siempre, desactualizados y descontextualizados, destacándose los enfoques conductistas.

Frente a una postura de la formación en gastronomía o culinaria en Colombia es poco lo que hay, se puede inferir de algunas pocas ponencias, repositorios, artículos y diplomados en docencia gastronómica que existen actualmente en el país.

En el artículo de prensa titulado, La gastronomía, un tema de patrimonio cultural y salud pública (2011) publicado en el Centro Virtual de Noticias de la Educación, se da cuenta del primer Congreso Internacional de Escuelas de Gastronomía, organizado por LCl - LaSalle College en el marco de la VI Gastronomía Corferias 2011, donde estudiantes, docentes y directivas de las escuelas de gastronomía de 9 países, así como representantes de la industria gastronómica colombiana y de los ministerios de Cultura, Turismo y Protección Social se dieron cita" para analizar la responsabilidad de la gastronomía con la salud pública, la industria y la formación de personas éticas que puedan desenvolverse en la sociedad" (Congreso Internacional de Escuelas de Gastronomía, 2011). En este Congreso también se dio espacio para reflexionar "sobre las necesidades de la industria gastronómica y hotelera frente a los programas de gastronomía y culinaria y se destacó la importancia de formar no solo chefs, sino banqueteros, meseros, maîtres y sobre todo, personas comprometidas con la gastronomía como patrimonio cultural de los pueblos" (Congreso Internacional de Escuelas de Gastronomía, 2011), también se invitó a las escuelas a reafirmar el papel de los restaurantes y hoteles en función de nuevas propuestas creativas y placenteras en el marco del auge turístico que vive actualmente el país, que permitan consolidar un turismo gastronómico, otras de las temáticas abordadas en el Congreso fue la necesidad de cocineros y gastrónomos con formación en cuestiones nutricionales, de salud pública, de turismo, de sustentabilidad y creativas que le permitan diseñar menús terapéuticos que mejoren la gestión alimentaria en los hospitales del país, rescatar y conservar el patrimonio alimentario del país, adaptar el repertorio alimentario al contexto turístico, administrar eficientemente y éticamente los recursos naturales y crear propuestas gastronómicas innovadoras.

El Congreso finalizó con unas charlas sobre el proceso de internacionalización y la importancia de la cooperación entre instituciones para la formación integral de los estudiantes, y también con el compromiso del lcetex de promover la generación de redes de cooperación y asesorar proyectos de internacionalización.

Es necesario aclarar aquí, que, aunque este Congreso no tenía como objetivo principal hacer una reflexión frente al quehacer formativo de la gastronomía vs culinaria, si permite entre sus temáticas, dar una idea de los conocimientos que requieren los perfiles en dicha disciplina, tomando como plataforma la globalización y el turismo. 
Otra ponencia que arrojan las bases de datos en el contexto colombiano, es la de las docentes Amparo Quijano y Samira Kadamani Abiyomaa (2010) de la Facultad de Diseño de la Universidad de los Andes, titulada: Comida colorida, experiencia y sensación, Una propuesta pedagógica de gastronomía y color y presentada en el marco del IX Congreso Nacional del Color, realizado en la Universidad de Alicante por la Facultad de Ciencias, el Departamento de Óptica, Farmacología y Anatomía, el Instituto Universitario de Física Aplicada a las Ciencias y las Tecnologías (IUFACyT) y la Universidad de Alicante.

En dicha ponencia se socializo "el desarrollo de una propuesta pedagógica, cuya metodología parte de la experiencia perceptiva del color en los alimentos" (Quijano y Kadamani, 2010). Este trabajo se aplicó en el curso de: Color, color y más color, que hace parte de las propuestas de formación integral que oferta la Universidad de los Andes.

En este se incorpora un modelo de aprendizaje interactivo como herramienta para la formación de procesos creativos y de innovación en los que se introducen los fundamentos de las teorías del color y sus aplicaciones en diseño. Es por ello que se plantea un ejercicio aplicado, el cual hemos denominado: Comida colorida, experiencia y sensación. Las dinámicas de esta práctica responden a interrogantes que consideramos claves para entender cómo el color es fundamental en los procesos cognitivos y perceptivos de los alimentos: ¿Por qué el color de algunos alimentos nos agrada?, ¿Por qué instintivamente rechazamos algunos alimentos con colores no convencionales?, ¿Cuáles compuestos proporcionan color a los alimentos? Estos y muchos otros interrogantes aparecen en la experiencia que diseñan con los alimentos nuestros estudiantes (Quijano y Kadamani, 2010).

Finalmente se concluye, que el color es uno de los primeros factores que se percibe y que motiva y condiciona la comestibilidad de los alimentos, también que los colores traen una carga moral valorativa, transferida por las per- cepciones particulares de los sujetos, sus experiencias previas y la fuerza de la historia. Se puede inferir de este trabajo otra apuesta por darle relevancia a la reflexión de los sentidos, en este caso en un curso particular, que toma como herramientas didácticas los alimentos para el estudio del color, sin embargo, este estudio no implica directamente la formación en gastronomía y culinaria, aunque sí propone, una teorización y práctica del ejercicio de los sentidos, que se debería abordar en los programas de formación gastronómica.

Otro artículo relevante para el análisis de la formación en gastronomía en Colombia, es el que propone la antropóloga Luz Marina Vélez Jiménez (2013), titulado: "Del saber y el sabor. Un ejercicio antropofilosófico sobre la gastronomía" y publicado en la revista Escritos de la Universidad Pontificia Bolivariana. Si bien este artículo no aborda directamente el tema de la enseñanza en la gastronomía, sí permite vislumbrar y abstraer desde una perspectiva antropológica, filosófica y ética, contenidos y posturas de objeto de estudio articulados a la gastronomía, que permitan dar cuenta de su ontología, epistemología y metodología. Vélez (2013) retoma la gastronomía en este artículo como: "elemento, hecho y fenómeno cultural, como producto de valores simbólicos y funcionales que propician el desarrollo y el bienestar de los grupos humanos" (Vélez, 2013, p. 171).

El presente artículo busca reflexionar sobre la convergencia de los conceptos "saber" y "sabor" en la gastronomía, desde las perspectivas antropológica (a partir del análisis cultural) y filosófica (a partir del análisis epistemológico). Este objetivo se sustenta en el postulado de la vigencia de la gastronomía como elemento, hecho y fenómeno cultural, como producto de valores simbólicos y funcionales que propician el desarrollo y el bienestar de los grupos humanos (Vélez, 2013, p. 173).

Para concluir, la autora reafirma el carácter transdisciplinario e interdisciplinario de la gastronomía, ya que: 
Se trata de un saber que autoafirma su condición bio-psicológica, su personalidad moral y la característica fundamental del grupo al que estos individuos pertenecen, en términos de talante, carácter y ethos, escenario donde se comprenden como productores y productos de un "horizonte de sentido" (Vélez, 2013, pp. 198-199).

En este artículo se observa el propósito por aclarar la concepción del saber gastronómico y sus posibles contenidos, enmarcada en el planteamiento de la condición transdisciplinar, multidisciplinar e interdisciplinar de la gastronomía, sin embargo, y como ya se ha mencionado, se retrata la realidad de la disciplina actual, que es concebida como:

'mercancía' tradicional, fusionada, recreada, (como"marca"y distintivo), suministrando ilusiones de identidad y actualidad a los comensales, valorando la egonomía, personalizando el consumo; a pesar de que ésta no se detiene en los fundamentos ontológicos que la definen, logra una especie de "conquista profesional" al convertirse en tema de la filosofía y de las ciencias sociales y humanas, que señala su prontuario de valores como experiencia vital del hombre de todos los tiempos. En esta medida, la gastronomía es una clave para el saber de sí de los grupos humanos -en términos de condición y posibilidad; de su relación con la animicultura y la agricultura; como conservadora de la vida; como medio moral; y como ética de mínimos y de máximos del existir y el subsistir- (Vélez, 2013, p. 199).

Se podría suponer entonces que el saber gastronómico en Colombia ha sido una disciplina que se ha condicionado al discurso capitalista, neoliberal y globalizado del mundo actual, que tiende a impartirse desde una articulación a la demanda laboral, y que, aunque actualmente haya un boom gastronómico en el país, existe aún desconocimiento frente a la delimitación conceptual y teórica entre culinaria vs gastronomía para efectos de formación.

Entre la poca documentación referenciada en Colombia con respecto a la temática en cuestión, se encuentra el repositorio de la estu- diante María del Pilar Castillo Pinilla (2012) para optar por el título de magíster en Pedagogía en la Universidad de La Sabana; en esta tesis se plantea una propuesta pedagógica aplicada a un caso particular, en este ejemplo se trata de la asignatura Microbiología y Conservación de Alimentos del Programa de Gastronomía de la Universidad de La Sabana.

Castillo Pinilla (2012) se planteó hacer un proceso de reflexión y mejoramiento frente a su práctica pedagogía como docente en el ámbito universitario, desde la "enseñanza para la comprensión", postulada por David Perkins con el proyecto ZERO (1968), así mismo, propone estrategias de formación enmarcadas en un enfoque que promueve la comprensión, definida como una habilidad de pensar y actuar con flexibilidad a partir de conocimientos previos. Afirma que, con este nuevo enfoque hubo la necesidad de reestructurar el currículo de la asignatura y diversificar las estrategias metodológicas y didácticas para el desarrollo de desempeños de comprensión.

La propuesta de este repositorio nace como una crítica implícita a la tendencia del enfoque conductista, que privilegia la clase magistral y el rol del docente en contraposición al alumno, también sugiere reevaluar dichas metodologías de memorización de contenidos, que lo único que promueven es una mecanización y fragmentación del conocimiento en detrimento de un conocimiento crítico, reflexivo, adaptativo y contextualizado. Otras de las sugerencias o necesidades que plantea Castillo Pinilla (2012), es que los docentes deben integrar los saberes teóricos y prácticos para propiciar una formación integral, haciendo énfasis en la responsabilidad que tienen los profesores, independiente del tema que impartan, de formarse en pedagogía y reflexionar sobre las competencias, la planeación y pertinencia de contenidos, las metodologías y didácticas, los propósitos, metas y evaluaciones de su proceso de enseñanza y también el nuevo rol que adquiere el alumno bajo el enfoque de la enseñanza para 
la comprensión, en el cual, este es, el centro de la enseñanza y cuya finalidad es la comprensión de temas o contenidos articulados con su cotidianidad y otros saberes o disciplinas que promueva un pensamiento analítico, crítico, creativo e innovador, que es lo que demanda el mundo hoy.

Aun cuando actualmente en Colombia y a través de las bases de datos se evidencia poca información con respecto a la reflexión pedagógica del ámbito disciplinar gastronómico, si se observan algunos esfuerzos por reconceptualizar la disciplina desde enfoques inter, trans y multidisciplinares, también por delimitarla frente al saber culinario, así como, por plantear y divulgar las necesidades pedagógicas frente a la formación de la gastronomía, como se puede constatar en la oferta de algunos diplomados en pedagogía y didáctica en gastronomía impartidas en instituciones, tales como la Universidad Externado de Colombia o la Universidad San Buenaventura de Cartagena, que aunque ofrecen una propuesta formativa para la gastronomía, terminan siendo casi siempre, los mismos diplomados que se imparten para profesionales de cualquier área, no licenciados.

\section{Resultados}

Finalmente, y después de este rastreo y análisis documental en la web sobre temas referentes a la formación y la gastronomía en el ámbito iberoamericano y colombiano, se observa que la disciplina gastronómica y su discurso formativo no se han consolidado formalmente, sin embargo, es en esta documentación donde se evidencia, de modo fragmentado e implícito, esfuerzos por plantear un punto de partida y un puente entre la discusión e investigación de la relación pedagogía-formación y gastronomía vs culinaria. También de esta producción intelectual se pueden deducir algunos retos que enfrentan actualmente la disciplina gastronómica y la educación, no solo en el ámbito iberoamericano, sino también en el colombiano:
1. Hay una concepción errónea y malinterpretada del término gastronomía vs culinaria, no solo entre la población en general, sino entre los mismos docentes y estudiantes de los programas de gastronomía y culinaria, malinterpretación que se ha perpetuado gracias a los medios de comunicación y a la exaltación del mal tomado concepto del "chef" / cocinero, en detrimento del gastrónomo profesional.

2. No se ha hecho una delimitación conceptual, metodológica y de contenidos clara, entre las técnicas, las tecnologías y las carreras profesionales en gastronomía vs culinaria. Aunque en teoría la profesionalización en gastronomía propone más investigación, es poco lo que se evidencia en las bases documentales frente a este tema y la percepción que queda es que, aunque los programas profesionales de gastronomía se propongan ser más extensos frente a las técnicas o las tecnologías, terminan siendo extensiones de estas, con contenidos repetitivos, mecánicos, fragmentados y enfrascados solo en el ámbito culinario y del saber hacer para el trabajo en detrimento de la reflexión y la comprensión para la disciplina gastronómica.

3. La tendencia a creer que para enseñar un tema solo basta con conocerlo, creencia popular entre el gremio gastronómico, quienes recientemente plantean la necesidad de formación pedagógica en los docentes de gastronomía y culinaria.

4. Las temáticas de investigación definidas dentro de la disciplina gastronómica y culinaria, que, aunque útiles para estructurar un discurso en torno a la disciplina, son monotemáticas y casi siempre responden a la reivindicación de una gastronomía específica como marcador cultural de una población tal. 


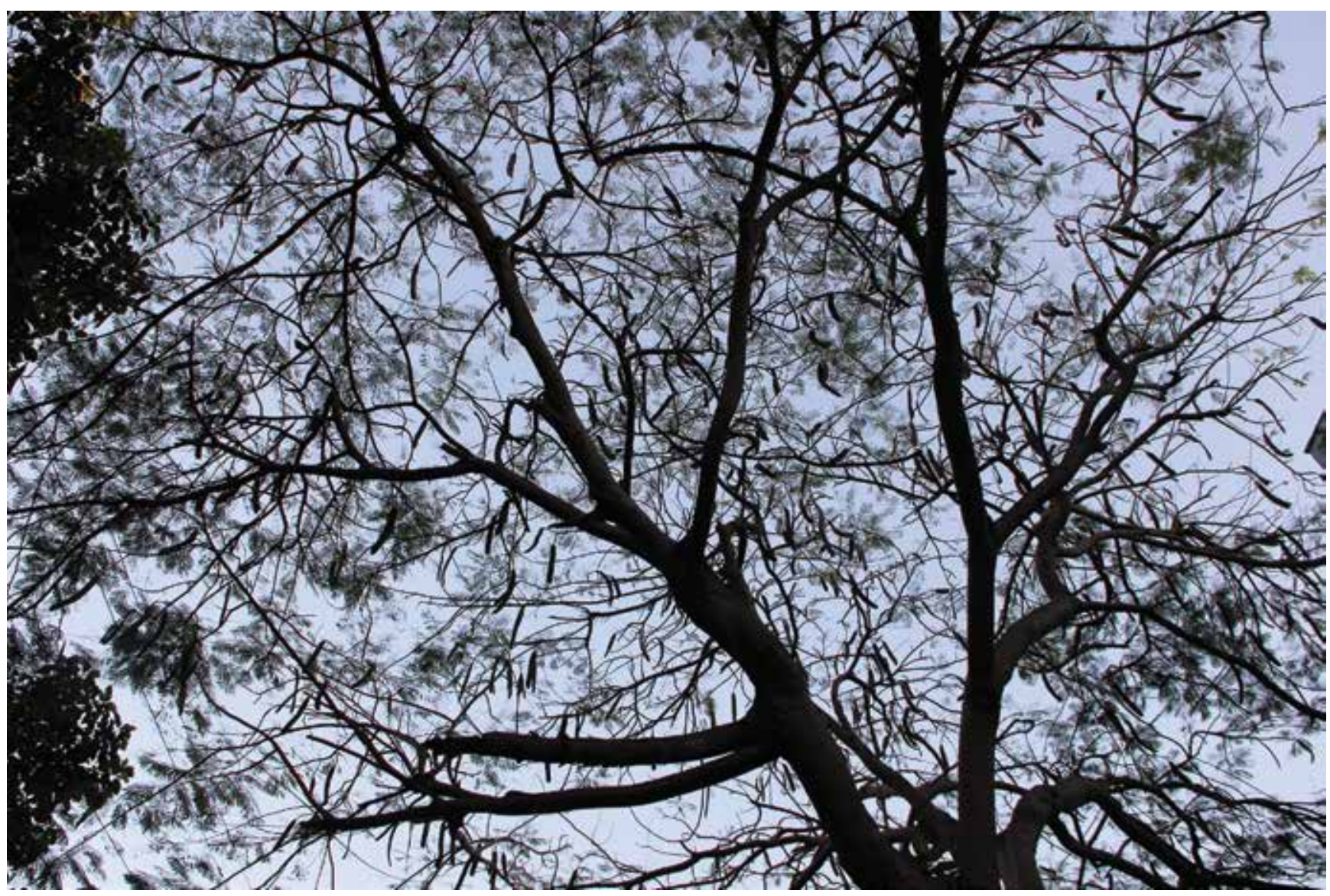

5. La tendencia a concebir el conocimiento de las distintas disciplinas como fragmentado e independiente de otros saberes en detrimento de una formación útil, transdisciplinar, interdisciplinar, multidisciplinar, flexible y contextualizada al mundo actual.

6. Que todavía hay mucho por hacer y proponer no solo en torno a la disciplina gastronómica, sino también en referencia a la educación.

7. Las exigencias de los perfiles profesionales actuales del gastrónomo no abogan por una reflexión gastronómica en sí misma, sino por amalgamar la gastronomía a la culinaria y mercantilizarla rápidamente en la fuerza laboral.

8. La falta de claridad en cuanto al campo de conocimiento y ejecución de la gas- tronomía, condicionado casi siempre, al ámbito culinario.

9. La falta de propuestas desde la gastronomía para consolidar su validez científica e investigativa.

En cuanto a producción bibliográfica iberoamericana y colombiana se refiere, son pocos los textos que dan cuenta de una relación directa entre formación y gastronomía, sin embargo, la investigación más explícita frente a la temática que se encontró, fue la publicada por Irma Muñoz Muñoz, Ana Leticia Tamayo Salcedo y Cesar Hernández Heredia (2012) para la revista electrónica Actualidades Investigativas en Educación de la Universidad de Costa Rica, en la cual dan cuenta...

de una investigación realizada en la Facultad de Turismo y Gastronomía de la Universidad Autónoma del Estado de México, a través de un estu- 
dio de educación comparada que se realizó con los 21 programas de formación profesional pública de gastronomía que se ofrecen en universidades estatales, universidades tecnológicas e institutos tecnológicos de México. Se analizaron las características del currículo formal, existiendo congruencia entre los distintos programas revisados y una orientación a la elaboración de productos gastronómicos. Se concluye que hay claridad en la función del profesional en gastronomía y la oferta educativa obedece a la necesidad de personal especializado para la administración y operación de establecimientos de alimentos y bebidas (Muñoz, Tamayo y Hernández, 2012).

En México y Brasil (como se analizó en apartados anteriores) es donde predomina la producción intelectual en torno a la formación en gastronomía, atendiendo al interés actual que genera desde las dinámicas del turismo. En estas propuestas se promueve el carácter multidisciplinar de la disciplina gastronómica y se evalúa la articulación y pertinencia de los currículos con los perfiles profesionales actuales. En España usualmente lo que predomina en cuanto a producción intelectual frente a la temática gastronómica son reflexiones en torno a la relación cultura, alimento y gastronomía desde la antropología social, el debate arte vs gastronomía, la formación de buenos hábitos alimentarios en los escolares y la relación ciencia, culinaria, química, gastronomía y arte, sin embargo, no se observan reflexiones o posturas en torno a la formación gastronómica en el contexto español, no obstante, y aun cuando explícitamente no aporten al ámbito formativo, sí pueden servir como punto de convergencia para postular el carácter interdisciplinar, multidisciplinar y transdisciplinar en la consolidación y formación de la gastronomía profesional.

Cabe resaltar que, en la mayoría de reflexiones iberoamericanas y colombianas en torno a la gastronomía con otras temáticas, casi siempre son los académicos de otras áreas quienes generan las discusiones para al discurso gastronómico. En otras palabras, disciplinas como, el turismo, el arte, la historia, la antropología, la sociología, la ecología, la química, la medicina, la nutrición, la administración y la biología han estado implicadas e implícitas en la construcción de la disciplina gastronómica.

Con respecto a documentación sobre el campo formativo en la gastronomía y su producción intelectual en Iberoamérica y Colombia, exceptuando Brasil y México, lo que arrojan las bases de datos de la web son propuestas desde las facultades de educación de las distintas universidades, para cursos y casos específicos donde se plantean estrategias didácticas desde la gastronomía y para la gastronomía, en la enseñanza de un determinado tema, desde distintos enfoques pedagógicos y formativos.

\section{Conclusiones}

Es desde estos distintos análisis que se podría plantear un punto de partida o una postura inicial frente a la reflexión del quehacer formativo de la gastronomía profesional en Colombia. Inicialmente se podrían analizar los distintos enfoques pedagógicos que predominan en las investigaciones planteadas de casos particulares, como la enseñanza para la comprensión, la enseñanza cooperativa, el aprendizaje significativo y considerarlas en la articulación del discurso formativo en gastronomía.

Se podrían también tomar en consideración para la problematización de la formación en gastronomía desde las tendencias pedagógicas en Colombia, expuestas en el artículo de Luis Alfonso Tamayo Valencia (2007) para la Revista Latinoamericana de Estudios Educativos de la Universidad de Caldas, en la cual se reflexiona la pedagogía como dispositivo:

Como un aparato instrumental de la ideología, un sistema significante que elabora sus propias normas a partir de otras disciplinas y construye una serie de instrumentos (reglas) para incidir en discursos no pedagógicos (Tamayo, 2007, p. 67). 
La pedagogía como disciplina: "La pedagogía asumida como la disciplina que conceptualiza aplica y experimenta los distintos conocimientos acerca de la enseñanza de los saberes específicos en una determinada cultura" (Tamayo, 2007, p. 69).

La pedagogía como disciplina reconstructiva:

Desde esta perspectiva, elaborada por el grupo de profesores de la U. Nacional bajo la dirección del profesor $C$. Federicci es preciso superar tres direcciones bajo las que se ha agrupado la pedagogía: Como conjunto de saberes que le otorgan su especificidad al oficio de educador y que tiene por objeto la enseñanza. La pedagogía es el arte de la enseñanza. Como conjunto de enunciados que, más que describir o prescribir formas específicas de proceder en la educación, pretenden orientar el quehacer educativo, confiriéndole su sentido. Este sentido puede ser buscado hermenéuticamente (¿qué es lo que estamos haciendo?) o ideológicamente (¿qué es lo que debemos hacer?) Y una tercera dirección que asume la pedagogía como una especie de conocimiento implícito que básicamente definiría cuáles son las formas de transmisión legítimas y cuáles son ilegítimas. Una pedagogía correspondería a una cierta delimitación de modos de enseñar considerados válidos dentro del conjunto muy amplio de todos los posibles modos de enseñar.

Esta variedad es problemática, nos dicen, y justifica cierto grado de desconfianza social y académica frente a la pedagogía y a los pedagogos. Este grupo trabaja la relación entre el conocimiento escolar y el extraescolar buscando su articulación a través de la idea de "juegos de lenguaje tomada de Wittgenstein.

Insisten también en pasar de pedagogías ascéticas basadas en el deber ser, lo formativo, lo prescrito, a pedagogías hedonistas que buscan desarrollar la voluntad sin contraponerla al deseo, en continuidad con este. El paso de una moral basada en la oposición entre deber o inclinación a una moral basada en la expresión de los deseos y su regulación para la interacción y la comunicación es la propuesta. Abordan "las fuentes de conocimiento" en la escuela: jerarquías y relaciones: para mostrar que, aunque se ha privilegiado la "cultura académica" existen otras fuentes de conocimiento (experiencia personal, la imaginación, el arte, las tradiciones no científicas, la analogía no formalizable) que deben ser tenidas en cuenta. Apoyados en Habermas se insiste en que la ciencia y la técnica no constituyen la única esfera de racionalidad desarrollada por la modernidad. También el derecho, la moral, la crítica artística puede ser y han sido terrenos de una argumentación racional elaborada, decantada por escrito y relevante para ciertas órbitas de la acción. La ciencia no es más que un sistema cultural entre otros (Tamayo, 2007, pp. 71-73).

Y la pedagogía en el enfoque constructivista:

El constructivismo reconoce un sujeto activo que llega a la escuela con una visión del mundo y una manera de actuar en él, que desencadena procesos de construcción de conocimiento o cambio conceptual, pero también actitudinal, metodológico, axiológico y estético. Asume la enseñanza como la construcción de escenarios que posibilitan esos cambios y direccionan el aprendizaje para que se oriente a la construcción de significados más potentes, adecuados y complejos (Tamayo, 2007, p. 74-75).

El constructivismo es más una posición epistemológica con consecuencias didácticas que una pedagogía, pero a partir de ella es posible construir un campo de saber que rastreando las prácticas de los maestros, sus métodos, procesos de aprendizaje, conocimiento escolar, desarrollo cognitivo y afectivo, axiológico y estético, permitan la elaboración de propuestas alternativas para el mejoramiento de la enseñanza (Tamayo, 2007, p. 74).

Desde el artículo de Tamayo Valencia (2007) y otros repositorios anteriormente analizados se puede iniciar la discusión en torno a las corrientes predominantes de la pedagogía en Colombia y su articulación a la formación profesional en gastronomía, lo importante es tener claro que independientemente de la temática que uno domine para efectos de enseñanza, es necesario formarse en el discurso y la práctica pedagógica, experimentar con estos enfoques y no dejarlos en la teoría, tener en cuenta tam- 


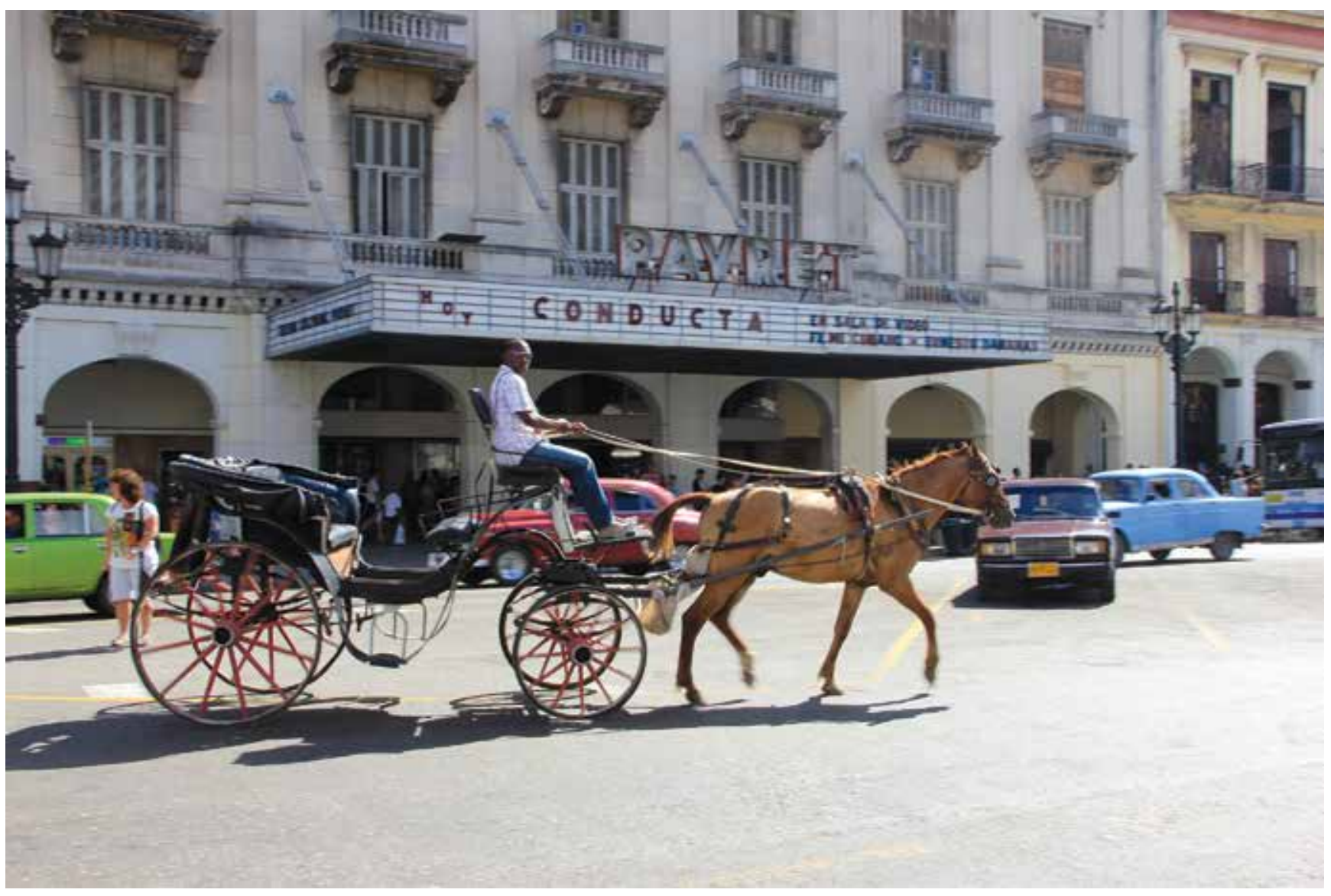

bién que no solo es cuestión de enseñar a memorizar conocimientos, sino también de enseñar a comprenderlos, representarlos y aplicarlo en la cotidianidad, así como evaluar la relevancia y articulación de los contenidos impartidos, con el mundo actual.

Se ve la necesidad que tiene la sociedad de tener profesionales con diferentes capacidades como: abstracción, análisis y síntesis, aplicación de los conocimientos en la práctica, comunicación oral y escrita, investigación, aprender y actualizarse permanentemente, crítica y autocrítica, para actuar en nuevas situaciones, identificar, plantear y resolver problemas, tomar decisiones, adicional a la responsabilidad social y compromiso ciudadano6 entre otras. "Lo que la sociedad del conocimiento pide son profesionales capaces de pasar del mero saber hacer al entendimiento profundo (explicación y comprensión). No solo la adquisición de un conjunto de conocimientos en una determinada área, sino al cultivo de la creatividad y la capacidad de la innovación (Castillo, 2012).
En al ámbito universitario es imprescindible que el docente conozca muy bien la disciplina que imparte para efectos de enseñanza, sin embargo, entre algunos de los docentes de los programas de gastronomía se observa un desconocimiento frente a la disciplina gastronómica vs la culinaria, y en esta malinterpretación donde se ha resentido la práctica pedagógica de la disciplina gastronómica. Es también necesario tener en cuenta que el docente de gastronomía no solo debe saber cocinar como se cree erróneamente, sino que también debe educarse en pedagogía y proponer nuevas dinámicas y posturas formativas frente a la gastronomía, planteando reflexiones en torno a estrategias y metodologías del proceso enseñanza-aprendizaje en la disciplina, para iniciar una postura formativa que se proponga a los docentes de los programas de gastronomía y que tengan en cuenta en su praxis pedagógica. La planeación de la asignatura, la metodología, la evaluación 
y los planes de mejoramiento articulados a las tendencias pedagógicas que se plantean en el mundo actual, también se debe tener en cuenta el creciente interés por la formación en, de y para los sentidos, y comprender que los conocimientos son útiles cuando se contextualizan en la cotidianidad.

Para finalizar, retomo el artículo de prensa del periódico El País de México, titulado "El futuro de la gastronomía está fuera de la cocina" (2015), en el cual se socializa la reunión que tuvieron algunos cocineros, biólogos y académicos en México para reflexionar sobre los desafíos del mundo de la comida y su evolución que permite acercarse a una nueva propuesta de la gastronomía como un método transdisciplinar, interdisciplinar y multidisciplinar que no solo se limita al ámbito culinario, sino que tiene un campo de acción mucho más amplio que se podría concebir y proponer holísticamente con otras disciplinas y saberes.

\section{Referencias}

Ayora, S. I. (2014). Antropología y performance. El performance de lo yucateco: cocina, tecnología y gusto. Alteridades, 24(48). México. Recuperado de http:// www.scielo.org.mx/scielo.php?script=sci_arttext\&pid $=$ S0188-70172014000200006

Barretto, M. (2005). Gastronomía y turismo. Historias detrás de las recetas. Estudios y Perspectivas en Turismo, 14(1). Ciudad Autónoma de Buenos Aires, Argentina.

Brillat-Savarin, J. A . ( 2014). La fisiologia del gusto. Barcelona: Obelisco.

Caldo, P. (2009). Pequeñas cocineras para grandes amas de casa... la propuesta pedagógica de Angel Bassi para las escuelas argentinas. Temas de Mujeres, Año 5, N 5, 33-50.

Carvalho, B. (2010). Entre panelas, livros e tradições: as trajetórias de formação do professor de gastronomía. (Tesis de maestría). Universidad Nove de Julho, São Paulo, Brasil. Recuperado de https://bibliotecatede.uninove.br/bitstream/tede/447/1/B_Beatriz\%20de\%20Carvalho\%20 Pinto\%20Rampim.pdf

Castillo, M. P. (2012). Mejoramiento pedagógico en el ámbito universitario. (Tesis de maestría). Universidad de La Sabana, Chía, Colombia.

Cifuentes, I. H. (2012). Guía metodológica del curso Gastronomía Guatemalteca por regiones de la escuela Taller de Hotelería Zunil para el fortalecimiento de la identidad nacional y la virtud del patriotismo. (Trabajo de grado). Universidad del Istmo, Guatemala.

Cristancho, M. F. (2013). El oficio del cocinero y la culinaria en Bogotá, mirada desde la experiencia de algunos chefs. (Tra- bajo de grado). Pontificia Universidad Javeriana, Bogotá, Colombia. Recuperado de https://repository.javeriana. edu.co/bitstream/handle/10554/12145/CristanchoCortesMariaFernanda2013.pdf?sequence $=1$

D' Humières, C. (2005, enero). La cultura del otro: español en Francia, francés en España. Ponencia presentada en el Encuentro Hispano - Francés de Investigadores, Sevilla, España.

Dreher, D. M. y Maria, Z. (2003). La calidad de vida de los profesionales en gastronomía. Movimientos de sueños, de limitaciones y de placer. Estudios y Perspectivas en Turismo, vol. 12, 290-309.

Ferreira, A. (2014, junio 21). La comida como herramienta pedagógica. Diario de gastronomía. Recuperado de http://diariodegastronomia.com/la-comida como-herramienta-pedagogica/Cynthia Arantes

Garrido, B. (2012). La cocina y la experiencia culinaria como proceso artístico y creativo. Creatividad y Sociedad, 19, $1-38$.

Hernández, H., Salcedo, C., Tamayo, A.L., Castro, D. y Muñoz, I. (2016). Tendencias gastronómicas predominantes en la produccion de revistas cientificas en Iberoamerica. Ciencia Ergo Sum, 23(1), 76-84. Recuperado de http:// www.redalyc.org/pdf/104/10444319009.pdf

LCl. (2011, octubre). La gastronomía, un tema de patrimonio cultural y salud pública. Ponencia presentada VI Gastronomía Corferias, Bogotá, Colombia.

Lima, R., y Souza, L. R. (2015). Gastronomia sustentável, formação do gastrônomo e desenvolvimento local. Revista Competencia, 8(2), 125-144. Disponible en: http://seer. senacrs.com.br/index.php/RC/article/view/253/231

López, M. (2016). (Re) aprender español con la gastronomía, propuesta didáctica. (Tesis de maestria). Universidad Internacional de La Rioja, La Rioja, España.

Luderer, C. (2012, mayo y junio). Las memorias culinarias vividas por estudiantes de un curso virtual de pedagogía: experiencias que contribuyen para una reflexión sobre el aprendizaje alimentario en las escuelas. Ponencia presentada en I Congreso Internacional Comer en la Escuela, Barcelona, España.

Mejía, L., Mejía, S., Bravo, M. (2014). Tendencias gastronómicas: La encrucijada entre lo tradicional y lo innovador. Culinaria, 8, 27-40. Recuperado de http://web.uaemex. mx/Culinaria/ocho_ne/PDF\%20finales\%208/Tendencias_gastronomicas.pdf

Melgar, S. (2013). La gastronomía en el sistema turístico. Buscando nuevos productos, mejorando destinos. El caso de la Isla de Fuerteventura. Pasos Revista de Turismo y Patrimonio Cultural, 11(2), 483-494.

Montes, H. (2014, junio 16). Estudiar gastronomía no es como lo pintan. EL Tiempo. Recuperado de http://www. eltiempo.com/estilo-de-vida/gente/estudiar-gastronomia-no-es-como-lo-pintan/14117675

Muñoz, I., Tamayo, A. L., y Hernández, C. (s.f.). Formación profesional de la gastronomía en instituciones públicas en México. Revista electrónica Actualidades Investigativas en Educación, 12(3), 1-18.

Nápoles, D. (2010). Sistema de actividades para el reforzamiento del valor. Responsabilidad en los estudiantes de la Escuela de Hotelería y Turismo "Hermanos Gómez". (Tesis 
de maestría). Universidad de Ciencias Pedagógicas "José Martí". Camagüey, Cuba.

Nullvalue. (1999, diciembre 2). Educación técnica y tecnológica hace carrera. El Tiempo. Recuperado de http://www. eltiempo.com/archivo/documento/MAM-957522

Oliveira, A. (2011). A formação do professor nos cursos de gastronomia: reflexões transdisciplinares. Ponencia presentada en Encontro Estadual de Didática e Prática de Ensino, Goias, Brasil. Recuperada de http://www2.unucseh.ueg.br/ceped/edipe/anais/ivedipe/pdfs/didatica/ co/37-63-1-SM.pdf

Orgeret, C. (2016). Aplicación didáctica del conocimiento sobre gastronomía en educación primaria. (Trabajo de grado). Universidad Internacional de La Rioja. La Rioja, España

Pérez, D. M. (2015, septiembre 22). El futuro de la gastronomía está fuera de la cocina. El País. Recuperado de http://cultura.elpais.com/cultura/2015/09/22/actualidad/1442889339_805601.html

Pinto de Menezes, M. C. (2005). A formação de alunos(as) num curso superior de gastronomia: aprendizagem, cultura e cidadania. (Tesis de maestria). Centro Universitario Nove de Julho. São Paulo, Brasil. Recuperado de https:// bibliotecatede.uninove.br/bitstream/tede/1087/2/B_ Maria_Cristina_PintoPde_Menezes.pdf

Quijano, A., y Kadamani, S. (2010, junio-julio). Comida colorida, experiencia y sensación: una propuesta pedagógica de gastronomía y color. Ponencia preesentada en IX Congreso Nacional del Color. Alicante, España. Recuperada de https://rua.ua.es/dspace/bitstream/10045/16478/1/ actas_IX_CNC_89.pdf

Sánchez, F. (2010, mayo). La función didáctica del periodismo gastronómico. Ponencia presentada en el Congreso de Comunicación "Alfabetización Mediática y Culturas Digitales". Sevilla, España.

Santos, N. (2013, noviembre). La enseñanza colaborativa (team teaching) como método para una educación integral: La experiencia del curso Los sabores de la escritura: Cultura gastronómica y literatura en Hispanoamérica. Ponencia presentada en V Simposio Internacional de
Estudios Generales, Puerto Rico. Recuperado de http:// www.rideg.org/wp-content/uploads/2014/04/Laense $\%$ C $3 \%$ B1 anza-colaborativa-team-teaching-comom\%C3\%A9todo-para-una-educaci\%C3\%B3n-integralLa-experiencia-del-curso-Los-sabores-de-la-escritura-. pdf

SENA. (2014, octubre 20). 50\% de chefs y cocineros de Colombia han pasado por el SENA. Sala de prensa del Sena. Recuperado de http://www.sena.edu.co/sala-de-prensa/ escrita/Paginas/Noticias/50-de-chefs-y-cocineros-deColombia-han-pasado-por-el-SENA.aspx

Sperandio, M. H. (2015). A formação superior em gastronomia: análise descritiva das dissertações de mestrado produzidas no Brasil. Revista Brasileira de Pesquisa em Turismo, 9(1), 156-173. Recuperado de https://www. researchgate.net/profile/Maria_Henriqueta_Gimenes_Minasse/publication/281413593_A_formacao_superior_em_gastronomia_analise_descritiva_das_dissertacoes_de_mestrado_produzidas_no_Brasil/ links/561958e208aea80367203139.pdf

Tamayo, L. A. (2007). Tendencias de la pedagogía en Colombia. Revista Latinoamericana de Estudios Educativos, 3(1), 65-76. Recuperado de http://www.redalyc.org/ pdf/1341/134112603005.pdf

Unesco. (2000). Desafíos de la educación. Buenos Aires: Instituto Internacional de Planeamiento de la Educación.

Unigarro, C. (2010). Patrimonio cultural alimentario. Quito: Fondo Editorial Ministerio de Cultura.

Vásquez, R. (1999). Francés culinario: ¿El prestigio del francés justifica su enseñanza en las licenciaturas en Gastronomía? Universidad Autónoma de Baja California. Recuperado de http://idiomas.mxl.uabc.mx/cii/cd/ documentos/V_12.pdf

Vélez, L. M. (2013). Del saber y el sabor. Un ejercicio antropofilosófico sobre la gastronomía. Escritos, 21(46), 171-200.

Zalles, A. M. (2015). Primera aproximación a una fundamentación teórica de la gastronomía como arte. Revista virtual Especializada en Gastronomía, No. 2, 45-55. Recuperada de http://web.uaemex.mx/Culinaria/pdf\%20 culinaria\%209/gastrononia_como_arte.pdf 